\title{
XVI.
}

Aus der medicinischen Klinik des Herrn Prof. Erb.

\section{Ueber die Veränderungen des sympathischen und cerebrospinalen Nervensystems bei zwei Fällen von Addison'scher Krankheit. \\ Von}

\author{
Dr. Wilhelm Fleiner, \\ Privatdocenten und Assistenten im Ambulatorium der medicinischen Klinik zu Heidelberg.
}

(Hierzu Tafel VI und 4 Autotypen im Text.)

Seit dem Erscheinen des Add is on 'schen Werkes ${ }^{1}$ ) iber die constitutionellen und localen Effecte der Nebennierenerkrankungen ist trotz des grossen Interesses, welches sowohl Kliniker als Pathologen und Physiologen dieser Frage entgegenbrachten, die Entstehung: des nach Addison benannten Symptomencomplexes und der Zusammenhang desselben mit pathologiscben Veränderungen der Nebennieren ein ungelöstes Räthsel geblieben.

Ich verzichte darauf, an der Hand der im Laufe der Jahre mächtig angewachsenen Literatur ${ }^{2}$ ) eine geschichtliche Entwicklung unserer Anschaungen über die Addison'sche Krankheit wiederzugeben, und beschränke mich nur auf die Bemerkung, dass bereits wenige Jahre nach der Addison'schen Publication sowohl das physiologische Experiment, als die klinisch-pathologische Erfahrung dahin entschieden hatten, dass zwischen Erkrankung der Nebennieren und bronzed-skin kein nothwendiger Zusammenhang existiren müsse.

Neben einer stattlichen Zahl von Fällen wirklicher Addisonscher Krankheit existiren doch einerseits solche, bei welchen trotz des im Leben anscheinend unzweideutigen Krankheitsbildes bei der Section die Nebennieren intact gefunden wurden, und andererseits Fälle, bei welcben trotz postmortal constatirten pathologischen Be-

1) On the constitutional and local effects of disease of the suprarenal capsules. Loudon 1855.

2) Vgl. H. Averbeck, Die Addison'sche Krankheit. Erlangen 1869.

Deutsche Zeitsehr. f. Nervenheilkunde. II. Bd. 
funden an den Nebennieren intra vitam keinerlei der Addison'schen Krankheit zukömmliche Symptome beobachtet worden waren. Auch angeborener Mangel der Nebennieren wurde beobachtet, ohne Addison'sche Krankheit.

Für manche Fälle der zweiten Kategorie darf vielleicht der Erklärungsversuch $\mathrm{H}$ u t chin s on's ${ }^{1}$ ) als gentigend zugelassen werden obwohl er für den einzelnen Fall weder bewiesen, noch widerlegt werden kann - , dass nämlich Patienten mit Nebennierenerkrankungen maligner (Carcinom), vielleicht auch acut entzündlicher Art (Hämorrhagien) früher sterben könnten, als die nur sehr langsam sich entwickelnde Hautpigmentirung Zeit fände, aufzutreten.

Ganz anders liegt aber die Frage bei den Fällen von bronzedskin ohne Nebennierenerkrankung. Die Addison'sche Erklärung durch eine nur functionelle Störung in den Nebennieren erscheint unzureichend, und man muss wohl annehmen, dass zwischen Erkrankung der Nebennieren und dem Auftreten der Hautpigmentirung ein Bindeglied nothwendig sei.

Schon Addison hat einer hochgradigen Veränderung des Solarplexus bei einem seiner Fälle (Dr. Qu eck ett) grosse Bedeutung bejgelegt, auch $\mathrm{Harley}^{2}$ ) und andere Experimentatoren führten die schweren Erscheinungen und den Tod nach Nebennierenexstirpation auf Verstimmelungen der grossen sympathischen Ganglien, besonders des rechten Semilunarganglions, zurtick. Immer mehr wurde von späteren Forschern der Schwerpunkt der pathologischen Veränderungen bei der Addison'schen Krankheit von den Nebennieren nach den Ganglien und Geflechten des Bauchsympathicus verschoben. So ist allmählich die Anschaung zur herrschenden geworden, dass zwischen den pathologischen Veränderungen der Nebennieren und der Entwicklung der klinischen Erscheinungen des Addison'schen Symptomencomplexes die grossen Bauchgeflechte des Sympathicus die Vermittlungsrolle spielen müissten.

Bei dem ausserordentlich grossen Reichthum der Marksubstanz der Nebennieren an Nervenfasern und Ganglienzellen, welche nach den Untersuchungen von Bergmann ${ }^{3}$ ), Ecker ${ }^{4}$ ), Kölliker ${ }^{5}$ ),

1) Medic. Times and Gazette 1856 u. 1858. Transactions of the Path. Soc. VIII u. IX.

2) An experimental inquiry into the function of the suprarenal capsules and their supposed connexion with bronzed skin. Brit. and foreign med. chir. Review. 1858. XXI. 204 u. $498 \mathrm{ff}$.

3) De glandulis suprarenalibus. Diss. Göttingen 1839.

4) Der feinere Bau der Nebennieren. Braunschweig 1846.

5) Gewebelehre. Leipzig 1867. S. 520. 
Luschka, Virchow ${ }^{1}$ ) u. A. mit dem Sympathicus in Verbindung stehen, konnte diese Anschaung an Wabrscheinlichkeit nur gewinnen. Auch der Zusammenhang der Nebennieren mit dem Centralnervensystem, wie er in jüngster Zeit namentlich durch die Untersuchungen Zander's ${ }^{2}$ ) erwiesen ist, dürte für die Theorie der Addison'schen Krankheit von nicht zu unterschätzender Bedeutung sein.

Pathologische Veränderungen an den sympathischen Ganglien finden schon bei $A d d i s o n^{3}$ ) Erwähnung in einem Falle, weleher von Dr. Queckett mikroskopisch untersucht wurde. In der Monographie Averbeck's werden diese Veränderungen der den Nebennieren benachbarten grossen sympathischen Nervencentren und des Sympathicus selbst als unwesentliche Sectionsergebnisse angefibrt, aber wenige Jahre später ist der merkwiirdigen Krankheit schon ein besonderes Kapitel in Eulenburg's und Guttmann's ${ }^{4}$ ) Pathologie des Sympathicus gewidmet. Während indessen Eulenburg und Guttmann nur eine verhältnissmässig kleine Zahl positiver Befunde am Sympathicus zusammenstellen konnten, baben sich in den letzten 2 Jahrzehnten die casuistischen Beiträge iiber Sympathicusveränderungen bei Addison'scher Krankheit derart gemehrt, dass v. Kahlde $n^{5}$ ) in seiner Habilitationsschrift schon 39 Fälle zusammenstellen konnte, bei welchen Veränderungen an den Semilunarganglien, an den Splanchnicis oder den Sympathicusgrenzsträngen angegeben waren. Indem ich auf diese Zusammenstellung v. Kah I d en's verweise, welche ich trotz eingehendster Durchsicht der Literatur nicht wesentlich erweitern konnte, betone ich, dass ausser v. Kahlden's eigenen Fällen nur wenige Befunde modernen und exacten Anforderungen entsprechen. Dasselbe ist der Fall bei denjenigen Fällen ${ }^{6}$ ), wo bei ausgesprochener Addison'scher Krankheit der Befund am Sympathicus negativ war. Es kann deshalb die Frage über die Abhängigkeit des Addison'schen Symptomencomplexes von einer Erkrankung des Sympathicus noch nicht als gelöst angesehen werden.

1) Virchow's Archiv. Bd. XII. 1857. - Berliner klin. Wochenschr. 1864. Nr. 9. Die krankhaften Geschwülste. II. - Virchow-Hirsch's Jahresberichte 1856-1860.

2) Ueber functionelle und genetische Beziehungen der Nebennieren zu anderen Organen, speciell zum Grosshirn. Ziegler's Beiträge zur path. Anat. u. zur allg. Path. Bd. VIII. S. $439 \mathrm{ff}$.

3) 1. c. S. 3.

4) Die Pathologie des Sympathicus auf physiologischer Grundlage. Berlin 1876.

5) Beiträge zur patholog. Anatomie der Addison'schen Krankheit. Virchow's Archiv. Bd. CXIV. S. $65 \mathrm{ff}$.

6) v. Kahlden, l. c. S. 77 u. 78. 
Im Gegentheile sind durch die experimentellen Untersuchungen Tizzoni's 1) „uber die Wirkungen der Exstirpation der Nebennieren auf Kaninchen" ganz neue Gesichtspunkte für die Beurtheilung der Addison'schen Krankheit gegeben worden, indem nach der Exstirpation der genannten Organe ein dem Addison'schen Symptomencomplex ähnliches Krankheitsbild sich entwickeln soll, welches auf weitgehende Veränderungen am gesammten Nervensystem zurïckzufübren sei.

Guido Tizzoni ${ }^{1}$, Ueber die Wirkungen der Exstirpation der Nebennieren auf Kaninchen.

Beim Kaninchen hat die Zerstörung einer oder beider Nebennieren über kurz oder lang den Tod zur Folge. Dem Tode geht ein Krankheitsbild voraus, in welchem man viele Symptome der Addison'schen Krankheit wiedererkennt, wie abnorme Pigmentirung, besonders der Mundschleimhaut, Verfall der Ernährung, nervöse Erscheinungen, wie Kräfteverlust, Coma, epileptiforme Krämpfe. Nach Tizzoni's Untersuchungen beruhen diese Symptome auf einer Alteration im Gross-und Kleinhirn, im Rükenmark und in den peripheren Nerven, welche im Wesentlichen charakterisirt ist durch weitgehende Zerstörung der Nervenfasern und Ganglienzellen, begleitet von Congestion, Störungen in der Lympheirculation, Alteration der Gefässwände, entzündilichen Infiltrationen und Hämorrhagien.

Im Rückenmark nimmt die Schwere dieser Veränderungen in dem Maasse ab, als man vom Cervical- nach dem Lendenmarke abwärts steigt; ihren grössten Grad erreicht sie im unteren Cervicalmark und im obersten Abschnitt des Dorsalmarks. Der Sitz dieser Veränderungen ist vorwiegend in der grauen Substanz und der Pia mater.

Im Gross- und Kleinhirn hat die beschriebene Veränderung mehr diffusen Charakter; im Bulbus hat sie ihren Sitz hauptsächlich am Boden des 4. Ventrikels und greift auch auf die daselbst localisirten Kerne des Vagus, Glossopharyngeus accessorius und Acusticus über. Im Rückenmark tritt sie zuerst im Centralcanal und dessen Nachbarschaft auf und erstreckt sich dann durch die graue und weisse Commissur zu den Vorderund Hinterhörnern. In der weissen Substanz des Rückenmarks kann sich sowohl eine systematische, auf die hinteren Stränge oder blos auf die Goll'schen Stränge beschränkte Degeneration, als auch eine von der Pia ausgehende Degeneration ohne bestimmten Sitz vorfinden.

$\mathrm{Zu}$ den genannten centralen Läsionen kann sich noch eine Zerstörung eines oder beider Hinterhörner hinzugesellen, welchen Veränderungen noch eine Degeneration der (gekreuzten) Vorderhörner folgen kann.

In den peripheren Nerven betrifft die Degeneration nicht alle Fasern, sondern nur einzelne; diese häufig der ganzen Länge nach oder nur stellenweise.

Bei Thieren, welche bald nach der Nebennierenexstirpation erlegen

1) Ziegler's Beiträge zur path. Anatomie u. allg. Pathologie. VI. 1889. Heft 1. 
Gehirn, Gehirnhäute, auch Rückenmarkshänte sind normal. Auffällige Veränderungen finden sich nur im Gebiete der Hinterstränge des Rückenmarkes, entsprechend den inneren Keilsträngen des Dorsalmarkes, weniger des Halsmarkes. Es finden sich daselbst beiderseits im äusseren Drittheil kleine Herde, welche zum Theil schon mit freiem Auge erkennbar sind. Bei mikroskopischer Untersuchung stellen sie sich dar als Anhäufungen von Zellen, theils Leukocyten, theils Wucherungsproducten der Neuroglia. Mit der zelligen Wucherung und Sclerose der Neuroglia ist ein gewisser Untergang von Nervenfasern verbunden. Den Herden entsprechend sind die Gefässe erweitert und prall mit Blut gefüllt.

Das Ganze erinnert an die Befunde bei secundärer Degeneration.

Babes et Kalindero ${ }^{1}$, Un cas de maladie d'Addison avec lésions des centres nerveux. Paris 1890. Prés. à l'acad. de méd. s. II. 1889.

Typischer Fall von Morbus Addisonii.

Die linke Nebenniere käsig und sclerosirt, die rechte atrophirt, fibrös und schwarz gefärbt.

Die Ganglien des Bauchsympathicus sind grösser, mehr pigmentirt als normal. Der sympathische Nervenplexus und besonders der Plexus solaris von faserigem, hartem, pigmentirtem Gewebe umschlossen; in dessen Nachbarschaft zahlreiche resistente Lymphdrüsen von der Grösse einer Haselnuss.

Bei der histologischen Untersuchung fehlen ausgesprochene Veränderungen am Sympathicus und dessen Ganglien, dagegen sind besonders beachtenswerth die Veränderungen am Rückenmark:

Die Rückenmarkshäute sind verdickt, dunkelbrann(?) und zeigen unter dem Mikroskope zahlreiche längliche und verästelte pigmentirte Zellen, besonders im hinteren Abschnitte des Rückenmarkes.

Nach der Härtung in Müller'scher Flüssigkeit beobachtet man am oberen Halsmark in der Höhe des 3. und 4. Halswirbels auf Querschnitten blassere, gelbliche Stellen in den seitlichen Theilen der Vorderstränge und in der Nähe der vorderen Wurzeln, ebenso in der Mitte der Hinterstränge und in den hinteren Wurzeln selbst.

In der Halsanschwellung und unterhalb derselben dehnt sich die beschriebene Veränderung so aus, dass nur noch die Goll'schen Stränge intact bleiben. Dem unteren Theile des Dorsalmarks entsprechend geht die Läsion auf den vorderen Theil der hinteren Wurzeln in den Seitensträngen über. Im Lendenmark wird die Läsion der Seitenstränge mächtiger, während sie gleichzeitig in den Hintersträngen an Ausdehnung abnimmt.

Mikroskopisch besteht diese Veränderung im Wesentlichen aus einer Dickenzunahme der Neuroglia und einer Gefässveränderung, welche durch Verdickung der Wand und Infiltration der perivasculären Räume mit hyalinen kugligen Zellen charakterisirt ist.

Die vorderen Wurzeln sind nahezu normal. Dagegen sind die hin. teren hochgradig verändert in der Weise, dass der für gewöhn-

1) Vgl. Cornil, Bulletin de l'acad. de méd. 1889. XXI. p. 277. 
Verānder. des sympath. u. cerebrospinal. Nervensyst. b. Addison'scher Krankh. 271

lich dünne Axencylinder häufig spindelförmige Anschwellungen zeigt; in der Nähe der Ranvier'schen Schnürringe ist er häufig unterbrochen oder zum Aeussersten verdünnt. In einzelnen Fasern, welche von zahlreichen, fettig granulirten Zellen umgeben sind, ist das Myelin zerfallen und der Axencylinder varicös geschwollen und schlecht gefärbt und oft unterbrochen, bisweilen spiralförmig aufgerollt.

Weiter unten zeigen auch die vorderen Wurzeln diese Veränderungen, und die Alteration der hinteren Warzeln wird hochgradiger. Sie enthalten nur noch wenige normale Fasern; an deren Stellen sind Züge von spindelförmigen, bisweilen granulirten, protoplasmatischen Zellen getreten.

Die kleinen Gefässe der Wurzeln haben hyalin degenerirte Wandung und sind umgeben von Haufen embryonaler Zellen.

Es besteht also eine chronische Sclerosirung des Rückenmarkes, welche wesentlich auf die Gegend der hinteren Wurzeln beschränkt ist, und eine Neuritis, welche besonders auf die hinteren Warzeln der Spinalnerven übergeht. Diese Neuritis ist besonders charakterisirt durch Degeneration von Nervenfasern, Anschwellung und stellenweise Unterbrechung der Axencylinder, körnigen Zerfall des Marks und Zellvermehrung. Im unteren Dorsalmark erreichen diese Veränderungen ihren höchsten Intensitätsgrad.

Ausser A begg und Babes a. Kalind ero berichteten sehon früher zwei Autoren über Veränderungen im Rückenmarke bei Addison'scher Krankheit: Burresi ${ }^{1}$ ) und Semmola. ${ }^{2}$ ) Bei dem Falle des Ersteren constatirte Prof. Brigi di: Hyperämie des Rückenmarks, Obliteration des Centralcanals durch Exsudat und Bindegewebe, Infiltration von weissen Blutkörperchen in den Gefässwänden, Erweiterung der perivasculären Lymphräume, Veränderungen der Ganglienzellen, Erweichung der weissen Substanz mit den gewöhnlichen Degenerationsformen der Nervenfasern und leichter Verdickung des Stroma. Diese Veränderungen nehmen im Rückenmarke von oben nach unten an Intensität ab. Der zweite Fall war insofern kein typischer von Morbus Addisonii, als die Nebennieren normal befunden wurden. Se mmola fand Degeneration der Abdominalganglien und Lymphzelleninfiltration in der Umgebung des Centralcanals des Rückenmarks und leitete hiervon die nervöse Natur der Addison'schen Krankheit ab.

Diese wenigen Beobachtungen können weder zur Bestätigung der Tizzoni'schen Angaben verwerthet werden, noch sind sie geeignet, die letzteren zu widerlegen. Um daher zu klaren Anschauungen tiber das Wesen der Addison'schen Krankheit gelangen zu können, namentlich um die Frage entscheiden zu können, ob ansser der Erkrankung der Nebennieren Veränderungen des Nervensystems dem

1) Morbo dell'Addison. Lo sperimentale. T. XLVI. 1890. p. 267.

2) Gazette hebdomadaire de méd. et de chir. 18\$1. 26. Aug. 
wechselvollen Krankheitsbilde zu Grunde liegen, ist es nothwendiges Erforderniss, bei allen vorkommenden Fällen eine systematische Untersuchung sowohl des sympathischen, als des spinalen Nervensystems vorzunehmen.

Dieser Aufgabe habe ich mich unterzogen, als ein ganz besonderer Zufall mir kurz nach einander zwei Fälle von Addison'scher Krankheit in ganz verschiedenen Stadien der Ausbildung in die Hände spielte.

Die Sectionsergebnisse des einen Falles habe ich, soweit sie makroskopisch interessante Veränderungen darboten, bereits veröffentlicht. (Berl. klin. Wochenschrift 1889. Nr. 51.)

Ausser den typischen Veränderungen des Morb. Addisonii bot aber der Fall so viele neue und wenig bekannte histologische Befunde, dass ich es kaum gewagt haben wirde, den Fall als einzigen in extenso zu publiciren und die Befunde dem Symptomencomplex der Addison'schen Krankheit hinzuzurechnen. Ich schicke infolgedessen seiner Beschreibung diejenige eines anderen Falles voraus, welcher, abgesehen von einer fungösen Ellbogengelenksentzlundung, keinerlei Complicationen des Addison'schen Krankheitsbildes darbot.

\section{Fall.}

Herr K. J., 42 jähriger Metzger und Wirth aus V., wurde am 22. November 1889 in die chirurgische Klinik zur Vornahme einer Ellbogenresection wegen fungöser Gelenkentzlindung anfgenommen. Ans der Vorgeschichte des Patienten ist zu entnehmen, dass sein Vater lungenleidend war, und dass er selbst in seinem 27. Lebensjahre an Drüseneiterungen am Halse und vor 4 Jahren an einem Abscess gelitten habe, welcher von einer cariösen Rippe seinen Ausgang genommen hatte. Der Abscess wurde incidirt, die Rippe resecirt; von der Operation ist bis zur Zeit eine kleine Fistel in der linken vorderen Thoraxpartie zuruckgeblieben.

Die Affection des linken Ellbogengelenks begann vor $1 \frac{1}{2}$ Jahr mit Schmerzen; seit etwa $1 / 2 \mathrm{Jahr}$ ist Patient wegen heftiger Schmerzen im Ellbogen und zunehmender Schwäche gänzlich arbeits unfähig.

Am Tage der Aufnahme ergab die Untersuchung, abgesehen von einer spindelförmigen, teigigen Anschwellung der linken Ellbogengelenksgegend und von Oedem des linken Vorderarmes, nichts Abnormes. Besonders waren über den Lungen keine Veränderungen nachweisbar, und auffällig war nur, dass bei normalem percutorischem Befund die Herztöne ausserordentlich schwach waren. Der Puls war ebenfalls sehr schwach, und die Temperatur betrug im Maximum nur $37^{\circ} \mathrm{C}$.

Von einer Hautpigmentirung ist in der Krankengeschichte nichts erwähnt.

Am 26. November 1889 wurde von Herrn Prof. Czerny die Ellbogengelenkresection vorgenommen. Weder bei der Operation, noch nach 
Veränder. des sympath. u. cerebrospinal. Nervensyst. b. Addison'scher Krankh. 273

derselben traten, abgesehen von einer nicht sehr erheblichen Temperatursteigerung, irgend welche beunruhigende Erscheinungen auf, doch erlag der Patient am Tage nach der Operation einem plötzlichen Tod durch Herzparalyse, and man nahm als Ursache der letzteren Chloroformwirkung an.

Auf dem Secirtische fiel eine abnorme Hautfärbung der Leiche auf, und als ich durch die Freundlichkeit von Herrn Prof. A rnold zur Besichtigung der Hantveränderung hinzugerufen worden war, konnten wir die Vermuthung eines vorliegenden Falles von Addison'scher Krankheit noch vor der Leichenöffnung aussprechen.

Sectionsprotokoll: Grosse, männliche Leiche; Haut im Allgemeinen blass, aber dunkel pigmentirt. Besonders starke Färbung zeigt die Haut in der Umgebung der Mamillae, am Halse und in den Achselhöhlen; die Hant der Genitalien ist braun. schwarz.

Auch ander Wangenschleimhaut sind einzelne braune Flecke.

Auf der linken Seite der Brust sind einige ziemlich stark eingezogene, aber verschiebliche Narben; auf einer derselben eine kleine Schorfbildung. Der dritten linken Rippe entsprechend eine $7 \mathrm{Cm}$. lange, aber gleichfalls verschiebliche Narbe; auch in der linken Achselhöhle eine 10 pfennigstückgrosse, etwas dunkel gefärbte, aber nicht so stark eingezogene Narbe. Ausgedehnte und stark pigmentirte Narben an der äusseren Seite des Handgelenks.

Das linke Ellbogengelenk spindelförmig aufgetrieben; Haut- und Unterhautzellgewebe infiltrirt. An der Aussenseite eine von oben nach unten verlaufende $15 \mathrm{Cm}$. lange, durch Nähte vereinigte Wunde. Haut der linken Hand ödematös.

Schleimhäute blass, Corneae ziemlich klar, Pupillen gleich weit.

Unterhautfettgewebe mässig entwickelt, Fett etwas dunkel gefärbt. Musculatur kräftig, rothbraun, glänzend.

Skelett gross und kräftig; Thorax stark gewölbt, unten flügelförmig. Zwerchfell links in der Höhe der 4. Rippe, rechts im 4. Intercostalraum.

Die 3. linke Rippe zeigt einen ausgedehnten Defect, der $5 \mathrm{Cm}$. von der Mittellinie des Sternum beginnt und nach aussen eine Ausdehnung von $9 \frac{1}{2} \mathrm{Cm}$. hat. Allerdings fehlt nur der vordere Theil der Rippe, wenigstens ist an der Hinterseite eine dünne, der Form der Rippe entsprechende Knochenlamelle vorhanden. Es entspricht diese Stelle der vorhin erwähnten horizontal verraufenden Narbe. Aus dem Sternalende der Rippe lässt sich eine käsige Masse ausdrücken; dieser Stelle entspricht die oben angeführte Borke.

Die Lungen collabiren ziemlich beträchtlich; sie zejgen oben und unten pseudomembranöse. Verwachsung der Pleurablätter. Die Pleurahöhlen sind beiderseits leer.

In der Herzbeutelhöhle trübe, stark gelb gefärbte Flüssigkeit. Im Pericard. viscerale mässige Fettentwicklung; zahlreiche Ekchymosen an Hinter- und Vorderfläche des linken Ventrikels. Endocard des linken Ventrikles, namenltich gegen die Aorta zu, sehnig getrübt. Zipfel der 
Mitralis an der Schliessungslinie verdickt. Musculatur bei mittlerer Weite der Höhle von mittlerer Dicke, rothbraun.

Endocard und Klappen rechts normal, abgesehen von einer leichten Verdickung der Tricuspidalis. Musculatur wie links.

Pleura, namentlich den Verwachsungen entsprechend, beiderseits mit zahlreichen Hämorrhagien durchsetzt.

In den Lungenspitzen beiderseits vereinzelte, grauschwarze und graugelbe Herde; sonst ist das Gewebe lufthaltig und elastisch, in den unteren Abschnitten blutreicher und feuchter.

Lage der Baucheingeweide normal, abgesehen von starker Auftreibung des Magens. Milz 15,5-8,5-3 Co. Kapsel gerunzelt, an der Oberfläche tiefe Kerbungen. Malpighi'sche Körperchen zahlreich und deutlich. Pulpa sehr blutreich und etwas weich. Am oberen Ende der Milz ein linsengrosses, gelbes Knötchen mit einer deutlich durchsichtigen Umhillung.

Die beiden Nieren etwas grösser; die Kapsel stellenweise etwas fester haftend. Rinde an einzelnen Stellen etwas eingezogen, sonst verbreitert und getrübt. In den geraden Harncanälchen gelbweisse Endlagerungen. Schleimhaut der Nierenbecken und Umgebung der Kelche von Ekchymosen durchsetzt.

Leber grösser, mässig blutreich, etwas icterisch gefärbt. Acinöser Bau undeutlich. Das Ganze etwas trübe und fettglänzend.

In der Schleimhaut des Magens und Darms zahlreiche Ekchymosen. Die Follikel der solitären, sowie der Peyer'schen Plaques vergrössert.

Die beiden Nebennieren vergrössert, von käsigen Massen durchsetzt, sehwielig verdickt. Linke Nebenniere $7-5-4 \mathrm{Cm}$. Rechte Nebenniere $10-6-4 \mathrm{Cm}$.

Der rechte Plexus solaris, resp. das rechte Ganglion semilunare gross, derb und mit der rechten Nebenniere durch derbes Gewebe verbunden. Das linke Ganglion semilunare ist noch grösser als rechts und ebenfalls mit der linken Nebenniere innig verbunden.

Harnblase, Prustata und Hoden normal. Das linke Ellbogengelenk ist resecirt. Sägefläche mit zerfallenen Granulationen bedeckt. Knochenmark schmierig und röthlich.

Anatomische Diagnose: Multiple tuberculöse Caries, Tuberculose der Nebennieren. Morbus Addisonii. Sepsis. Multiple Hämorrhagien. Trübe Schwellung von Leber und Nieren.

Nach den Angaben der Krankengeschichte und des Sectionsprotokolls handelt es sich im vorliegenden Falle um Addison'sche Krankheit, welche durch multiple Caries und fungöse Ellbogengelenksentzündung complicirt war. Das erstere Krankheitsbild hatte in der vorwiegend nur die chirurgischen Veränderungen berücksichtigenden Krankengeschichte keine Erwähnung gefunden, doch war dessen hervorragendes Merkmal der Hautpigmentirung so deutlich ausgesprochen, dass aus derselben die Diagnose noch vor der Leichenöffinung gestellt werden konnte. Der Leichenbefund bestätigte diese Diagnose und ist aus ihm ersichtlich, dass es sich um 
einen ganz einwandsfreien, wohl ausgesprochenen Fall von Addison'scher Krankheit handelte, welcher durch zufällige Folgen der Operation zur Autopsie kam, ehe noch der Entwicklungsgang der in Rede stehenden Krankheit seinen endgiltigen Abschluss erreicht hatte. Aus diesem Grunde werden die Untersuchungsergebnisse dieses Falles eher werthvoller, als beeinträchtigt.

Zur mikroskopischen Untersuchung habe ich die Nebennieren, die Semilunarganglien, dẻn Bauchsympathieus, den Brustsympathicus mit den beiderseitigen Nerv. splanchnic. maj. et min. und den Halssympathicus verwendet und zwar in der Weise, dass ich von den beiderseitigen Grenzsträngen die hauptsächlichsten Ganglien und Zwischenstücke aus verschiedenen Stufen in Schnitte zerlegte. Ferner verwendete ich Intervertebralganglien aus verschiedenen Höhen der Hals, Brust- und Lendenwirbelsäule, ausserdem das Rückenmark mit der Cauda equina, den Nerv. vagus, ischiadicus, cruralis mit einem Hautaste. Ausserdem wurden Hautstücke aus verschiedenen Körperbezirken, Mundschleimhaut und sämmtliche Organe mit Ausnahme des Magendarmcanals und des Knochenmarks der Untersuchung unterworfen.

Ueber die Untersuchungsergebnisse werde ich im Folgenden berichten.

\section{Die Nebennieren.}

Beide Nebennieren sind vergrössert und von käsigen Massen durchsetzt, schwielig verdickt. Die Maasse der linken betrugen 7-5-4 Cm., die der rechten Nebenniere $10-6-4 \mathrm{Cm}$.

Zur mikroskopischen Untersuchung wurden mehrere Würfel so ausgeschnitten, dass womöglich neben den käsigen Herden auch noch anscheinend normales Gewebe erhalten wurde.

Von letzterem waren indessen an den mikroskopischen Schnitten nur noch spärliche Reste nachweisbar. Nur ganz kleine Inseln der Zona glomerulosa liessen sich da und dort noch erkennen. Wo die Epithelzellen noch wohlerhalten waren, zeigten sie grossen, blasstingirten Kern in feinkörnigem, trübem, fast gleichmässig gelbbräunlichem Protoplasmaleibe. Das interstitielle Bindegewebe ist fast überall kleinzellig infiltrirt und dadurch verbreitert. Nach der Peripherie der noch normalen Gewebeinseln nahm die Infiltration rasch zu und ging in Granulationsgewebe über. Der Infiltration des interstitiellen Gewebes entsprechend, hatten die Parenchymzellen gelitten; ihre Kerne waren blasser geworden oder gar nicht mehr gefärbt, ihr Protoplasma körnig zerfallen.

Im Granulationsgewebe waren zahlreiche epithelioide Zellen und in nicht unbeträchtlicher Zahl Riesénzellen vorhanden, in der für tuberculöses Gewebe charakteristischen Form mit randständigen Kernen. In den Riesenzellen und an vielen Stellen im Gewebe zerstrent $\mathrm{T}$ uberkelbacillen. Zerfallserscheinungen im Granulationsgewebe überall und in allen Abstu. fungen bis zur Nekrose und Verkäsung. Zwischen Granulationsgewebe und Käseherden an vielen Stellen breite Zonen hyalinen, mehr derben und fibrösen Gewebes. Eine deutliche Abgrenzung nach aussen war nicht mehr erkennbar; an manchen Stellen war wohl durch eine solche hyaline Gewebeschicht die Grenze nach dem umgebenden Fettgewebe gebildet, mei- 
stens aber gegen unregelmässige Züge von Granulationsgewebe weit in das Fettgewebe hinaus. Auch zerstreute Inseln von Granulationsgewebe lagen da und dort im Fettgewebe, in deren Innerm grössere und kleinere Gefässe, bisweilen auch kleine Nervenstämmchen erkennbar waren. Das Perineurium zeigte dabei gewöhnlich Infiltration mit Rundzellen, und Weigert-Präparate liessen Degeneration der Nervenfasern erkennen.

In einzelnen Arterienluminibus inmitten solcher Granulationsgewebeherde war Thrombusbildung zu constatiren; ausserdem zahlreiche kleine Hämorrhagien.

Die Gefässe in den tuberculösen Nebennieren waren ausserordentlich blutreich. Auffallend war auch dieser Blutreichthum und die Ektasie der Capillaren in dem die Nebennieren umgebenden Fettgewebe.

\section{Plexus solaris. (Semilunarganglien.)}

Die beiden Semilunarganglien sind beträchtlich vergrössert, sehr derb und mit den entsprechenden Nebennieren durch derbes Gewebe fest verbunden. Auch unter sich sind sie mit einander durch quer verlaufende

Fig. 1.

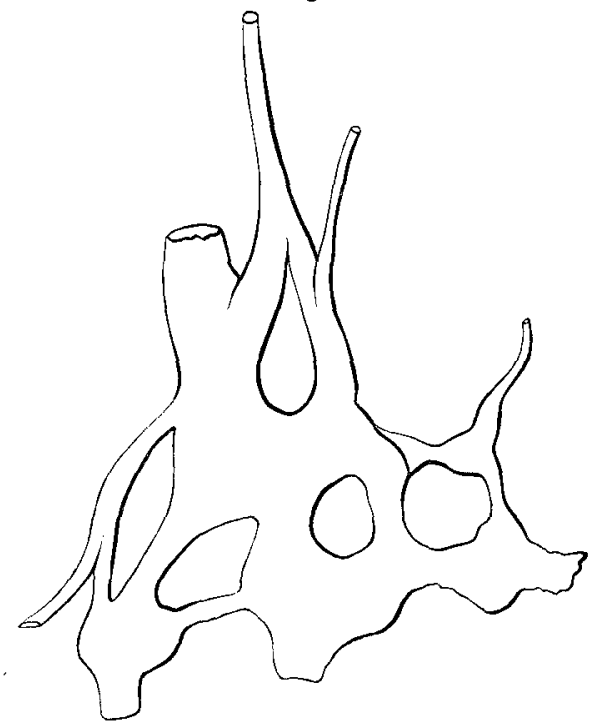

Gangl. semilun. sinist. (Natür). Grösse.)
Fig. 2.

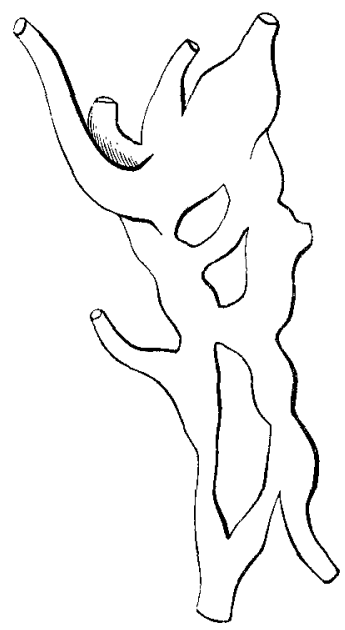

Gangl. semilun. dext (Naturl. Grösse.)

Nervenäste verbunden, so dass die Bezeichnung Plexus solaris eigentlich richtiger wäre, als rechtes und linkes Semilunarganglion. Der Medianlinie entsprechend habe ich die beiden Theile des Plexus getrennt und zum Härten im Zusammenhang mit der entsprechenden Nebenniere, dem Grenzstrang und den Splanchnicis gelassen, wodurch es ermöglicht wurde, die mikroskopische Untersuchung stufenweise vorzunehmen und den $\mathrm{Zu}$ sammenhang der gefundenen Veränderungen festzustellen. 
Veränder. des sympath. u. cerebrospinal. Nervensyst. b. Addison'scher Krankh. 277

Genaue Grössenangaben des Plexus waren wegen der complicirten Form und Gestaltung so grossen Schwierigkeiten unterworfen, dass ich auf Messungen vorzichtete und an deren Stelle Skizzen der betreffenden Theile vorgenommen habe. (Vgl. Fig. 1 und 2.)

Von beiden Semilunarganglien habe ich an verschiedenen Stellen nach der Härtung in Müller'scher Flüssigkeit und Alkohol Würfel ausgeschnitten, in Celloidin eingebettet und von letzteren Längs- oder Querschnitte hergestellt.

Die mit kernfärbenden Mitteln, besonders mit Boraxcarmin behandelten Schnitte zeigten zunächst nach aussen eine Abgrenzung durch eine breite, sehr zellreiche bindegewebige Kapsel.

Von dieser gingen in das umgebende Fettgewebe zahlreiche und mächtige, ebenfalls sehr zellreiche Züge, welche an vielen Stellen ausgebreitete $R$ undzelleninfiltration zeigten. Besonders ausgeprägt war die letztere in der Umgebung der zahlreich vorhandenen Gefässe und der zu den Nebennieren resp. zu den Ganglien führenden Nervenstämmchen. Die Gefässe waren an Zahl und Grösse auffallend mächtig; an den Capillaren und Venen trat eine Dilatation und beträchtliche Blutfüllung deutlich hervor.

Schon bei der Besichtigung mit freiem Auge waren die Infiltrationsherde als dunkler gefärbte Punkte zu erkennen: in grösster Zahl lagen dieselben ausserhalb der Kapsel und markirten den Verlauf von Gefässen und Nervenstämmchen. Vereinzelt lagen sie in der Kapsel selbst und da gewöhnlich in der inneren, zellreicheren, dem Ganglion zugewendeten Schicht. Auch im Innern der Ganglien waren solche Herde da und dort im Gewebe zerstrent mit freiem Auge zu erkennen.

Bei der mikroskopischen Untersuchung (vgl. Fig. 3) ergab sich, dass die intraganglionär gelegenen Herde, ähnlich wie die im periganglionären Gewebe gelegenen, in gewissen Beziehungen zu den Bindegewebszügen, bezw. zu den daselbst verlaufenden Gefässen standen. Bei einigen war ein Zusammenhang mit der Kapsel zul erkennen, bei anderen liess sich ein solcher Zusammenhang nicht nachweisen, und es lagen dann die kleinen Infiltrationsherde anscheinend circumscript im Innern der Ganglien in der Peripherie eines Gefässes. Degenerationserscheinungen, wie epithelioide Zellen, Riesenzellen u. dgl., fehiten, auch waren Tuberkelbacillen in solchen Herden nicht nachweisbar. Es handelte sich somit nicht um tuberculöso Ausstreuungen, sondern um einfache locale Entzündungserscheinungen.

Die interstitiellen, septenartigen Bindegewebszüge, welche sich von der Kapsel abzweigen und dem nervösen Theil der Ganglien als Stützgewebe dienen, zeigen ein wechselndes Verhalten.

An vielen Stellen sind sie schlank und bestehen aus einer faserigen Grundsubstanz mit spindelförmigen Zellen in mässiger Zahl. An anderen Stellen dagegen sind sie bis zu einem nicht unerheblichen Grade verbreitert durch grösseren Reichthum an Zellen. An vielen Stellen nimmt das Gewebe den Charakter von jungem Bindegewebe, Granulationsgewebe an.

Die Gefässe sind in den normal erscheinenden Bindegewebssepten bezüglich ihrer Structur und ihres Inhalts kaum verändert. Dagegen zeigten kleine Arterien und Capillaren den Infiltrationsherden entsprechend nicht 
unerhebliche Veränderungen. Schon der Inbalt derselben war stellenweise verändert, indem die Zahl der weissen Blutkörperchen eine gesteigerte war und der Zahl der rothen bisweilen gleich kam oder selbst prävalirte. Sehr oft waren an diesen Stellen die weissen Blutkörperchen wandständig geworden und bildeten dann und wann zusammenhängende, thrombenähnliche Massen.

An den nervösen Theilen der Ganglien sind schon bei schwacher Vergrösserung Veränderungen nachzuweisen, insofern als einzelne Gruppen oder Haufen von Ganglienzellen theils durch stärkere Pigmentirung der Ganglienzellen selbst, theils durch grösseren Gehalt der Ganglienzellenkapseln an stark gefärbten Zellen ausgezeichnet sind.

Was zunächst die Kapseln der Ganglienzellen anbelangt, so sind dieselben nicht, wie die Abbildungen bei A. Key und G. Retzius angeben, oder wie normale Präparate dies zeigen, von einem Kranz von Zellen mit regelmässig angeordneten, rundlichen Kernen umgeben, sondern die Anordnung der Kapselzellen ist eine ganz unregelmässige geworden, indem sich Rundzellen zwischen und um dieselben herumgelagert haben.

Von dieser Rundzelleninfiltration ist entweder nur ein Theil der Kapselwand betroffen, oder die ganze Kapsel ist inmitten eines solchen Infiltrates eingebettet. An manchen Zellen ist durch den Infiltrationsprocess die Kapselwand scheinbar verdickt und besteht aus mehreren Lagen von Zellen, an anderen Stellen scheint die Kapsel selbst weniger betheiligt, und nur das zwischen den Kapseln gelegene Bindegewebe ist kleinzellig infiltrirt.

Dieser Entzündungsprocess ist, wie ich noch besonders hervorheben muss, nicht gleichmässig und diffus durch das ganze Ganglion verbreitet, sondern tritt nur herdweise auf und umfasst Gruppen von Ganglienzellen, welche in der Nähe von alterirten Gefässen oder in der Nähe von Entzündungsherden liegen.

Die Ganglienzellen selbst füllen nur selten den Kapselraum ganz aus; gewöhnlich sind sie retrahirt und geschrumpft, so dass entweder nur Fortsätze ihres Protoplasmakörpers an die Kapselwand da und dort herantreten, oder dass sie nur an einer Seite der Kapselwand wie angedrückt anliegen. Selten liegt die Zelle so central, dass zwischen ihrer Peripherie und der Kapselinnenfläche ein Raum frei bleibt. Der durch Retraction des Zellprotoplasmas oder durch wandständige Lagerung und Schrumpfung der Zelle freigewordene Raum der Kapsel ist oft leer; bei der Mehrzahl der Zellen aber enthält er ein Exsudat in Form von Hyalinen, oft körniger Substanz, und vereinzelten Rundzellen. Viele Kapseln enthalten gar keine Zelle mehr, sondern sind angefüllt mit einer homogenen, structurlosen, hyalinen Scholle.

Die Kerne der Ganglienzellen sind bei erhaltenen Zellen gross, rund und bläschenförmig, gewöhnlich nur schwach gefärbt; ein Kernkörperchen nicht immer nachweisbar. Das Zellprotoplasma ist gleichmässig körnig und enthält bei der überwiegenden Mehrzahl der Zellen ein feinkörniges, glänzendes Pigment von gelbbrauner Farbe. Wo das letztere nur in relativ geringer Menge vorhanden ist, liegt es nur auf einer Seite oder an beiden Polen des Kernes. Bei Zunahme des Pigments an Masse drängt es den 
Veränder. des sympatb. u. cerebrospinal. Nervensyst. b. Addison'scher Krankh. 279

Kern zur Seite und macht ihn wandständig, oder aber es umschliesst denselben vollständig. Wo die ganze Zelle mit Pigment angefüllt ist, erscheint dieselbe dunkelbraun, an Weigert-Präparaten nahezu schwarz; der Kern ist dann nicht mehr sichtbar. Gewöhnlich sind die stark pigmentirten Zellen kleiner als die pigmentarmen oder pigmentfreien Zellen.

Manche Ganglienzellen sind ganz geschwunden, namentlich deu oben beschriebenen Entzündungsherden entsprechend. Man erkennt wohl im infiltrirten Gewebe dann noch deutlich die Form der Kapsel der Ganglienzelle, sie ist aber nur mit einer hyalinen Scholle oder mit Exsudat und spärlichen Rundzellen angefüllt. Von Protoplasma, Zellkern oder Pigment ist aber nichts mehr nachweisbar.

Von den Nervenfasern des Plexus zeigen vor allen die markhaltigen Fasern augenfällige Veränderungen.

Am deutlichsten und auffälligsten sind diese Veränderungen an der breiten Kategorie der markhaltigen Fasern zu erkennen, besonders an Weigert-Präparaten, deren Schnittrichtung in die Längsaxe solcher Fasern gefallen ist.

Beim Verfolgen einer solchen Faser zeigt sich deren Contour höchst unregelmässig durch kugelige oder spindelförmige Auftreibungen an einzelnen und abnorme Dünnheit an anderen Stellen. Oft folgen aufgetriebene, normal breite and verdünnte Stellen so regelmässig auf einander, dass die Faser dadurch ein rosenkranzähnliches Aussehen annimmt. An anderen Stellen oder an anderen Fasern ist das Aussehen ein regelloseres geworden dadurch, dass das Mark vielfach zerklüftet und in grössere und kleinere Schollen, sogar kleinste Körner zerfallen ist, wodurch vielfache Unterbrechungen in der Continuität der Faser zu Stande gekommen sind. Vielfach sehen auch die seitlichen Begrenzungen der Fasern höchst unregelmässig, wie angefressen, zackig aus - etwa einem Striche vergleichlich, den man mit spitzer Feder auf feuchtem Fliesspapier vornimmt. Wieder bei anderen erweckt es den Anschein, als ob nur an den Stellen der Ranvier'schen Schnürringe linsenförmige Ueberreste der Marksubstanz übrig geblieben wären.

Auf Querschnitten durch Nervenbündel im Plexus solaris sind (bei Weigert-Präparaten) die einen Neurilemmhüllen ganz leer, die anderen ganz ausgefüllt mit einer structurlosen Masse: Schwand der Fasern - Quellung. - Wieder andere Fasern enthalten bei gleichem Querschnitt der Neurilemmscheide Ueberreste des Marks in Form einer dünnen Ritze, oder in Form eines mehr oder weniger excentrisch gelegenen Tropfens, oder in Form unregelmässiger Körner und Schollen.

Die schmalen markhaltigen Fasern zeigen genau dieselben Erscheinungen des Markzerfalls, wie an den breiten beschrieben worden ist, nur erfordern die Einzelheiten derselben stärkere Vergrösserung zur Beobachtung.

Mit Boraxcarmin gefärbte und mit Salzsäurealkohol differenzirte Präparate zeigen, dass nicht nur die Markscheiden degenerirt sind, sondern dass auch die Axencylinder theils durch Auftreibungen, theils durch Schwund mehr oder weniger deutliche Veränderungen zeigen. Solche Auftreibungen der Axencylinder haben mitunter grosse Aehnlichkeit mit spindelförmigen Zellen. Obwohl durch dies Verhältniss die Frage, ob überhaupt 
Kernwucherungen an den Nervenfasern vorkommen, bisweilen erschwert wird, glaube ich doch eine solche stellenweise erkannt zu haben. Allgemein verbreitet, wie die Degeneration der Markscheiden und der Axencylinder, ist sie indessen nicht.

Was schliesslich den Zustand der marklosen, grauen Fasern anbetrifft, so ist eine Deutung des Befundes in dieser Beziehung so ausserordentlich schwierig, dass ich mir ein endgültiges Urtheil uber das Verhalten derselben nicht habe bilden kơnnen. Es lässt sich dieser Mangel wohl entschuldigen durch die bisher nur äusserst spärlichen Untersuchungen auf diesem Gebiete. Dass übrigens bei so ausgebreiteter Degeneration von Nervenfasern im Plexus solaris nur die markhaltigen der Zerstörung anheimfallen, während die grauen marklosen aus irgend einem Grunde frei ausgehen sollen, lässt sich indessen kaum annehmen. Quantitativ ist die Degeneration der markhaltigen Fasern zweifellos unverhältnissmässig viel ausgebreiteter, als die der marklosen Fasern. Weitere Untersuchungen werden aber erst über diese Verhältnisse näheren Aufschluss geben können.

\section{Bauch-Sympathicusgrenzstränge.}

Die Grenzstränge des Bauchsympathicus bereits makroskopisch in hohem Grade verändert. In einer Ausdehnung von $7-8 \mathrm{Cm}$. ist der Grenzstrang beiderseits dünn und atrophisch; die Dicke desselben beträgt kaum 1/4 vom Querschnitt des Brustsympathicus etwa in der Höhe des Abgangs der Splanchnici. Ganglionäre Anschwellungen des Grenzstrangs sind in dieser atrophischen Strecke mit freiem Auge nicht zu sehen. Bei der mikroskopischen Untersuchung sind Ganglien aber doch nachweisbar gewesen, obwohl dieselben vereinzelt und ausserordentlich klein waren.

Ehe ich nun wieder die Beschreibung dieser Ganglien vornehme, habe ich hervorzuheben, dass bei der ersten Besichtigung der mikroskopischen Präparate der Reichthum der Nerven und des sie umgebenden Gewebes an Blutgefässen ein auffallender ist. Dieselben sind fast ausnahmslos mit Blut gefüllt, insbesondere im Perineurium. Ausserdem sind die Capillaren des die Nerven umgebenden Fettgewebes mit Blut stark injicirt und erweitert. Viele dieser Gefässe, namentlich kleine Arterien, zeigen eine nicht unbeträchtliche Dickenzunahme der Wandung; bei einzelnen ist die intimale und mediale Haut hyalin degenerirt, während die Adventitia kleinzellig infiltrirt ist.

Die Ganglienzellen in den Ganglien der atrophirten Nervenpartie zeigen im Grossen und Ganzen dieselben Verhältnisse, wie im Plexus solaris. Die Zellen sind ganz versehieden gross; ihr protoplasmatischer Leib füllt die zugehörige Kapsel nicht mehr aus, sondern hat sich retrahirt und liegt entweder excentrisch der Kapsel an, oder aber er ist noch central gelegen und steht durch Fortsätze von versehiedener Form und Grösse mit der Kapsel in Verbindung. In den dadurch entstandenen Räumen sind hyaline Tropfen, feinkörnige oder structurlose schollige Massen, ab und zu auch Kerne nachweisbar. Vacuolenbildung innerhalb der Ganglienzellen ist ebenfalls öfters zu beobachten. Die Pigmentanhäufung in den Zellen erreicht ganz beträchtliche Grade und wird selten bei einer Zelle 
vermisst. Bei Weigert-Präparaten nehmen wegen dieses grossen Pigmentgehaltes die Zellen ganz schwärzliche Färbung an. Kerne sind sehr oft nicht mehr nachweisbar.

Infiltrationen der die Kapseln umgebenden Bindegewebszüge, wie sie im Solarplexus vielfach und ausgebreitet vorhanden waren, sind hier stellenweise nur angedeutet oder feblen gänzlich.

Im Stamme des atrophirten Sympathicus sind wohlerhaltene markhaltige Fasern, weder breite noch schmale, fast gar nicht mehr vorhanden. Die Stellen, an welchen die Fasern verliefen, sind nur noch angedeutet durch unregelmässige, theils fadenförmige, theils zackige, körnige Marküberreste, welche nur noch sehr schwer bei der Weigert'schen Hämatoxylinfarbungsmethode den Farbstoff aufnehmen und denselben bei der Differenzirung äusserst leicht wieder abgeben. Erst nach vielfachen, anscheinend missglitckten Färbungsversuchen habe ich mich zur Annahme entschliessen können, dass es nicht ein Fehler in der Methode, sondern die maximale Degeneration der markhaltigen Fasern war, welche den fast negativen Ausfall der Färbung verschuldet hatte. Auch auf Querschnitten bestätigt die Weigert'sche Färbungsmethode, dass nur unscheinbare Ueberreste markhaltiger Fasern ubrig geblieben sind. Die Bilder, welche Carminpräparate geben, entsprechen durchaus dem bereits beschriebenen Befund; von Axencylindern ist fast nichts mehr nachzuweisen. Eine Kernwucherung ist in den atrophischen Partien nicht ausgesprochen und deutlich nachweisbar; es handelt sich also lediglich um eine reine degenerative Atrophie mit nur sehr geringer Bindegewebswucherung, und zwar hat der Degenerationsprocess vorwiegend die markhaltigen Fasern nmfasst, während die Remak'schen Fasern unverhältnissmässig wenig gelitten haben.

Bei der Untersuchung von Längs- und Querschnitten des Sympathicus, welche ans oberhalb der atrophischen Partie gelegenen Stufen entstammen, beobachtet man ein allmähliches Abnehmen der degenerativen Vorgänge in den markhaltigen Fasern. Der schollige und körnige Zerfall des Markes ist zwar im oberen Bruchtheil des Sympathicus immer noch recht erheblich, doch nicht mehr so enorm, wio in dem tiefer liegenden atrophischen Abschnitt. Es sind auch hier wieder vorwiegend die breiten markhaltigen Fasern, welche die typische Form der Waller'schen Degeneration darbieten, während die schmalen markhaltigen Fasern geringere Veränderungen zeigen. Die Ganglienzellen zeigen dagegen dieselben Intensitätsgrade der Pigmentatrophie, wie in tieferen Abschnitten und wie im Solarplexus. Eine ausserordentlich grosse Zahl von Ganglien ist so reich an Pigment, dass sie bei Weigert'scher Färbungsmethode ganz schwarz tingirt werden.

\section{Brustsympathicus.}

Wenn man absieht von einem anscheinend grösseren Volumen des mittleren Abschnittes des rechten Brustsympathicns, so sind mit freiem Auge an den Grenzsträngen des Brusttheils keine auffälligen Veränderungen nachweisbar.

Bei der mikroskopischen Untersuchung fallen zunächst mächtige Hämorrhagien ins Auge, welche an beiden Grenzsträngen, namentlich aber am rechten stattgefunden baben.

Deatsche Zeitschr, f. Nervenheilkunde. II. Bd. 
Der grösste dieser hämorrhagischen Herde erstreckt sich, nach den Stufenschnitten am rechten Grenzstrang zu urtheilen, auf eine Länge von etwa $2 \mathrm{Cm}$. und hat vorwiegend in der bindegewebigen Hialle des Grenzstrangs seinen Sitz. Eine hämorrhagische Infiltration umgreift den ganzen Stamm und reicht noch weit hinaus in das umgebende Fettgewebe. Ein kleinerer Herd liegt im Stamme des rechten Grenzstrangs, ein ebensoleher in einem grösseren, vom Grenzstrange abgehenden $Z$ weige. Zahlreiche kleine Nervenstämmchen in der Nähe der erwähnten Herde zeigen unter dem Perineurium eine hämorrhagische Infiltration in der Weise, dass die Nervenfaserbündel vom Perineurium durch eine mehr oder weniger breite Schicht rother Blutkörperchen getrennt sind.

Da nun im Bereiche der Blutungen die Gestalt der rothen Blutkörperchen noch woblerhalten ist und noch keine Pigmentbildung, auch noch keine besonders hervortretende Veränderung der Nerven in der Nachbarsehaft der Blutungen stattgefunden bat, ist anzunehmen, dass es sich um frische, vielleicht sogenannte agonale Blutungen handelt.

Die Veränderung der Gefässe, Verdickung der Wand mit hyaliner Degeneration, vorwiegend der intimalen und medialen Hant, ist dieselbe, wie im Bauchsympathicus bezw. Plexus solaris. An einzelnen Ganglienhaufen ist sie ganz besonders deutlich ausgesprochen. Der Gefässreichthum im Sympathicus, die Hyperämie in demselben und in dem umliegenden Fettgewebe ist ganz eclatant.

Die Degeneration der markhaltigen Fasern ist im Brustsympathicus annähernd dieselbe, wie bereits beschrieben; vielleicht, doch nicht mit Sicherheit, ist ein gradueller Unterschied in der Degeneration zwischen Brust- und Bauchsympathicus vorhanden. Jedenfalls fehlt bei ersterem die hochgradige Atrophie, welche der Bauchsympathicus darbot.

Die Ganglienzellen weisen alle Stadien der Pigmentdegeneration auf; an den Weigert'schen Präparaten erscheinen die meisten Ganglienzellen schwarz.

Ein wesentlicher Unterschied zwischen linkem und rechtem Brustsympathicus liegt nicht vor. Auch linkerseits sind kleinere Blutungen vorhanden, wenn anch nicht in der Ausdehnung, wie auf der rechten Seite.

\section{Nervi splanchnici.}

Bei der Präparation der beiderseitigen Nervi splanchnic. maj. et min. zeigen sich makroskopisch keine Veränderungen; sie sind in reichliches Fettgewebe eingebettet und erscheinen auf dem Durchschnitt grauröthlich.

An den mikroskopischen Präparaten, namentlich an den nach Weigert's Methode gefärbten Schnitten fällt zuerst eine sehr weitgehende und hochgradige Degeneration markhaltiger Nervenfasern auf. Diese Degeneration ist nicht gleichmässig durch die Nervenstämme - welche ich stufenweise an Längs- und Querschnitten untersuchte - verbreitet.

Das Perineurium ist entschieden verdickt, das in den Nervenstämmen verlaufende Bindegewebe erscheint der Quantität nach ebenfalls vermehrt. Die Gefässe im Perineurium und ebenso im sclerosirten Bindegewebe zeigen bei praller Füllung der Lumina mit Blut eine nicht unerhebliche Ver- 
Verănder. des sympath. u. cerebrospinal. Nervensyst. b. Addison'scher Krankh. 283

dickung der Wandungen, deren einzelne Schichten aber wegen hyaliner Degeneration der letzteren nicht mehr deutlich von einander zu differenziren sind. Anhäufungen von Rundzellen sind nur selten angedentet oder fehlen bereits gänzlich.

Was die Degeneration der markhaltigen Nervenfasern anbelangt, so ist sie an den Splanchnicis womöglich noch hocbgradiger, als am Sympathicus selbst. Alle Stadien des Markzerfalls, bis zum vollständigen Schwund desselben, sind auf Längs- und Querschnitten in der beschriebenen und abgebildeten Weise typisch ausgeprägt. (Fig. 4.)

Bei den Carminpräparaten sind zahlreiche Schwann'sche Scheiden ganz leer und haben verschieden weites Kaliber. Da und dort befinden sich in denselben noch Reste einer stark lichtbrechenden Substanz und schwach tingirte Körperchen von unregelmässiger Form, welche von Axencylindern herrïhren dürften. Andere Neurilemmhüllen enthalten mächtigere, unförmliche, oft spindelähnliche Massen, welche den gequollenen Axencylindern entsprechen und Farbe angenommen haben. Viele sind von solchen gequollenen Axencylindern ganz ausgefüllt.

Da wo Faserbündel ausgefallen sind, zeigt sich besonders an Querschnitten Bindegewebsvermehrung und Kernwucherung. $O b$ es sich aber um wirkliche Bindegewebsvermehrung und Kernwucherung handelt, ist an manchen Stellen sehr schwer zu entscheiden, weil man sich immer den Einwand vor Augen halten muss, dass nur präexistente Bindegewebsfasern und Zellen durch Ausfall nervöser Elemente näher zusammengeschoben sein könnten.

An Intensität nimmt die Degeneration markhaltiger Fasern mit zunehmender Entfernung von den Semilunarganglien nicht ersichtlich ab. Beim Eintritt des Splanchnicus major in den Grenzstrang ist sie noch annähernd dieselbe, wie dicht über den erwähnten Ganglien.

Halssy mathicus.

Die beiderseitigen unteren Halsganglien bieten schon mit freiem Auge zu erkennende Grössenunterschiede dar zu Gunsten des linken Ganglions, welches etwa dasselbe Volumen erreicht, wie das rechte oberste Halsganglion.

An den Schnitten nimmt man an Carminpräparaten schon makroskopisch rundliche und längliche stärker gefärbte Herde wahr, welche, wie das Mikroskop zeigt, Bindegewebswucherungen in der Umgebung der Gefässe entsprechen. Im linken Gangl. cervic. inf. sind diese Bildungen häufger und zahlreicher als rechts; uberhaupt ist in diesem Ganglion das Bindegewebe viel mächtiger entwickelt, als irgendwo sonst im Sympathicus, und ich glaube, dass die auffällige Grösse des Ganglion dieser Bindegewebszunahme zuzuschreiben ist.

Die Herde in der Umgebung der Gefässe tragen den Charakter zellreichen jungen Bindegewebes. Tuberculöse Anzeichen, welche ich aus dem makroskopischen Verhalten vermuthete, fehlen gänzlich, nur ist hervorzuheben, dass einzelne Herde hyalin degenerirt sind.

Die Ganglienzellen sind an Grösse mindestens ebenso verschieden, wie im Semilunarganglion; die Pigmentirung ist dieselbe, und ebenso haben zahlreiche Zellkerne ihr Tinctionsvermögen verloren. 
Die Ganglienzellenhaufen zeigen ähnlich, wie die Gefässe, an verschiedenen Stellen eine Wucherung von zellreichem Bindegewebe in ihrer Umgebung. Das ganze Gewebe des Ganglion ist hyperämisch, am auffälligsten den Ganglienzellgruppen entsprechend.

An den Nervenfasern sind dieselben Degenerationsprocesse, wie an tieferen Partien des Sympathicus, nachweisbar. An breiten markhaltigen Fasern sind die Ganglien auffallend arm.

Ueber die zweiten Cervicalganglien des Sympathicus ist bezüglich der Grösse und des mikroskopischen Verhaltens nichts Besonderes erwähnenswerth.

Dagegen zeigen sich wieder in den beiden oberen Halsganglien Grössenunterschiede, indem das linke entschieden voluminöser ist, als rechts.

Die Veränderungen bezüglich der Gefässe, des Bindegewebes, der Ganglien und der Nervenfasern sind genau dieselben wie beim 3. linken Cervicalganglion, bezw. beim Semilunarganglion. Graduell ist die Degeneration markhaltiger Nervenfasern im Halssympathicus vielleicht etwas geringgradiger, als im Bauchsympathicus, doch sind dies Verhältnisse, welche sich nur sehr schwer abschätzen lassen, auf welche infolgedessen auch nur beschränkter Werth zu legen ist.

Irgend ein Moment, welches die überwiegende Grösse des linken Gangl, supremum hervorgerufen hat, liess sich übrigens bei der mikroskopischen Untersuchung nicht ausfindig machen. Es mag deswegen die Grössendifferenz der oberen Halsganglien als eine rein individuelle und nicht pathologische angesehen werden.

Was nun die zu den oberen Halsganglien, bezw. was die von denselben abgehenden Nervenstämmchen betrifft, so boten einzelne derselben ganz normales Verhalten dar, während andere, ebenso wie Sympathici und Splanchnici, Degeneration markhaltiger Nervenfasern erkennen liessen.

Zum Schlusse hebe ich noch hervor, dass bei Vergleichspräparaten von normalen Sympathicis Degenerationen von markhaltigen Fasern nicht zu beobachten waren; ebensowenig zeigten solche Präparate Gefässveränderungen und Bindegewebswucherungen von der beschriebenen Art und Weise. Pigmentablagerungen in verschiedenen Graden waren an Vergleichsobjecten in den sympathischen Ganglienzellen wohl sehr häufig vorhanden, niemals aber in der Intensität und Extensität, wie bei den beschriebenen Präparaten.

Man muss daher die hochgradige Pigmentatrophie der Ganglienzellen, die Alteration der Gefässwände, die Blutungen und die entzündliche Granulations- und Bindegewebswucherung in deren Umgebung und vor allen Dingen die hochgradigen Degenerationsprocesse an den markhaltigen $\mathrm{Fa}$ sern als pathologisch ansehen.

\section{Die intervertebralen (Spinal-)Ganglien. (Vgl. Fig. 5.)}

Die intervertebralen oder spinalen Ganglien, welche ich verschiedenen Höhen des Cervical-, Dorsal- und Lumbalmarks sammt Wurzeln und peripherem, gemischtem Nerve der Leiche entnommen habe, ergaben bei makroskopischer Besichtigung keine prägnanten Veränderungen. Sogar die Grössenunterschiede, welche bei dem später zu beschreibenden Falle ganz eclatant waren, waren nicht deutlich ausgesprochen. 
Veränder. des sympath. u. cerebrospinal. Nervensyst. b. Addison'scher Krankh. 285

Dagegen zeigen sämmtliche Spinalganglien, welche ich der mikroskopischen Untersuchung unterwarf, hochgradige histologische $\nabla$ eränderungen.

Die Kapsel der Ganglien ist mächtig verdickt und ausserordentlich zellreich. Eine äussere Schicht trägt den Charakter eines fibrösen und nur mässig zellreichen Bindegewebes; eine innere Schicht dagegen enthält sehr zahlreiche, mit Blut prall gefüllte Gefässe und ist reich an runden und spindelförmigen Zellen, dazu ausserordentlich stark pigmentirt.

Das Pigment besteht aus stark glänzenden, gelbbraunen Körnern, welche theils in rundlichen und spindelförmigen Zellen eingeschlossen sind, theils frei in den Spalten und Lücken des Bindegewebes lagern und daselbst netz- und sternförmige Figuren bilden. An den nach Weigert's Methode gefärbten Präparaten hat dieses Pigment, ganz ähnlich wie die rothen Blutkörperchen und das Pigment in den Ganglienzellen des Sympathicus und der Spinalganglien, schwärzliche Farbe angenommen.

Die Gefăsse der Kapsel sind an vielen Stellen von einem Hofe von Rundzellen umgeben. An einzelnen Präparaten sind frische Hämorrhagien in der Kapsel vorhanden, welche die Lücken und Spalten des Bindegewebes auf weitere Strecken infiltriren.

Von der inneren, zell- und pigmentreichen Schichte der Kapsel ziehen nach dem Innern der Ganglien vielfache grössere und breitere Züge, welche dieselbe Beschaffenheit zeigen. Ueberhaupt ist das bindegewebige Stützgewebe der Ganglien viel mächtiger und zellreicher, als in der Norm; ausserdem vielfach pigmentirt und an manchen Stellen von kleinen Herden von Rundzellen durchsetzt, welche bisweilen einen Zusammenhang mit Gefässscheiden erkennen lassen.

Die Ganglienzellen der Spinalganglien sind beträchtlich verändert. Nur wenige haben ihre Form behalten und zeigen noch tingirbaren Kern. Die meisten sind in mehr oder weniger hochgradiger Weise geschrumpft, zeigen Vacuolenbildung und eine Pigmentirung, welche häufig eine solche Intensität erreicht, dass an Weigert-Präparaten die ganze Zelle schwarz gefärbt, oder an Carminpräparaten die ganze Zelle von braunem Farbstoff angefüllt erscheint. Die Grösse der Zellen steht fast durchweg mit der Intensität der Pigmentirung im umgekehrten Verhältniss, in der Weise, dass die kleinsten, d. h. am meisten geschrumpften Zellen am meisten Pigment enthalten. (Pigmentatrophie.)

Die durch Schrumpfung der Zelle freigewordenen Theile des Kapselraumes sind vielfach leer; vielfach enthalten sie auch hyaline Massen und fibrinähnliche Fäden, oft anch zellige Elemente, Rundzellen. Manche der Kapseln enthalten nur structurlose, hyaline Schollen.

Die Kapsel der Ganglienzellen ist selten nur von einer Reihe von Zellen umgeben, wie dies an normalen Präparaten der Fall ist. Gewöhnlich sind die Zellen in mehreren Schichten vorhanden und ausserdem noch die Wandung mit Rundzellen infiltrirt.

Der Gehalt der Spinalganglien an Nervenfasern ist ausserordentlich wechselnd. Grosse Partien des Ganglion sind ganz frei von markhaltigen Fasern. Es sind in dieser Hinsicht besonders die peripheren Segmente der Ganglien zu nennen, welche an Kapselpartien grenzen, an welchen der geschilderte entzündliche Infiltrationsprocess und die Pigmentirung 
einen höheren Grad erreicht. Aber auch im Innern der Spinalganglien sind grössere Gebiete ganz frei von Nervenfasern, ohne dass sich dort regelmässig ein hochgradiger Entzündungsprocess nachweisen liesse.

Von den im Ganglion verlaufenden Nervenfasern sind zweifellos viele intact oder nur wenig verändert. Viele zeigen indessen die Zerfallserscheinungen des Markes in ganz analoger Weise, wie beim Sympathicus und Splanchnicus beschrieben wurde. Ausserdem sieht man an den zum Ganglion tretenden (hinteren Wurzeln) und aus dem Ganglion (zum gemischten Nerv) kommenden Nervenstämmen, dass eine grosse Zahl von Nervenfasern fehlen, also gänzlich degenerirt sind. Auf weite Strecken sind die Degenerationserscheinungen an den Fasern zu verfolgen, welche zum Rückenmark oder zum gemischten Nerv und zum Sympathicus hinziehen. Quantitativ ist die Degeneration von Nervenfasernam grössten an dem vom Sympathicus kommenden Stamme, dann in der hinteren Wurzel, am geringsten im gemischten Intercostalnerv.

Diezum gemischten Nerven tretenden vorderen Wurzeln des Rückenmarks zeigtenkeine Degenerationserscheinungen. An einigen grösseren Stämmen waren auch inmitten des Nervs frische Blutungen nachweisbar. In einem Falle hatte eine solche Blutung ihren Ausgang von einem grösseren, innerhalb des Nervenstammes verlaufenden Gefässe mit bochgradig veränderter Wandung genommen.

In den Spinalganglien selbst habe ich grössere Blutungen nicht gesehen, nur in den Kapseln verschiedener Ganglien waren frische hämorrhagische Infiltrationen nachweisbar.

Fasst man den ganzen Befund an den Spinalganglien zusammen, so muss man denselben bezeichnen als Folgen einer chronischen Entzündung, welche an den Gefässen ihren Ausgang nimmt, im Wesentlichen interstitiell verlänft und zu Verdickung und kleinzelliger Infiltration der Kapsel und des interstitiellen Bindegewebes führt, von Hämorrhagien begleitet ist und zu Pigmentablagerung führt. Hierzu gesellt sich als wahrscheinliche Folge der Entzündung eine Pigmentatrophie der Ganglienzellen und eine nicht unerhebliche Degeneration markhaltiger Nervenfasern. Dabei ist anfällig, dass sich die Degeneration auf die vom Sympathicus zum Ganglion tretenden und auf die vom Ganglionzum Rückenmarkverlaufenden hinteren Wur. zeln, also auf die sensiblen Fasern beschränkt, während die motorisehen vorderen Wurzeln intactbleiben.' (Vgl.Fig. 6.)

\section{Das Rückenmark.}

Bei der Herausnahme des Rückenmarks zeigt sich die Pia mater stark hyperämisch, sonst aber nicht wesentlich verändert, wenigstens nicht getribt und nicht verdickt.

Die Substanz des Rückenmarks ist ebenfalls sehr blutreich, mässig feucht und weich und quillt an den Schnittflächen stark hervor. Graue und weisse Substanz sind deutlich gezeichnet und wohl von einander zu unterscheiden, bieten aber frisch der Leiche entnommen keine wesentlichen Veränderungen dar. Dasselbe gilt für die vorderen und hinteren Wurzeln, die Cauda equina mit inbegriffen. 
Veränder. des sympath. u. cerebrospinal. Nervensyst. b. Addison'scher Krankh. 287

Die Eröffnung des Schädels wurde von den Angehörigen nicht erlaubt und musste somit eine Untersuchung des Gehirns und der Medulla oblongata unterbleiben.

Schon nachdem das Rückenmark wenige Tage in Müller'scher Flüssigkeit gelegen hatte, machten sich auf den Querschnitten desselben bestimmte Zeichnungen bemerklich. Ich habe dieselben nach der vollendeten Härtung in Müller'scher Flüssigkeit und Alkohol in natürlicher Grösse in den Figuren $7 \mathrm{a}-f$ wiedergegeben.

Während sich die graue Substanz des Rückenmarks in ihrer ganzen Länge in Müller'scher Fltissigkeit charakteristisch färbte und auch die weisse Substanz der Vorderstränge und Seitenstränge und ein Theil der Hinterstränge die charakteristische grünliche Farbe annahmen, blieben bestimmte Felder der Hinterstränge blass. Die eigenthümliche Anordnung dieser Felder und vor allen Dingen der Umstand, dass ich dieselben in ganz analoger Weise bei einem zweiten Falle von Addison'scher Krankheit verfärbt fand, erweckte die Vermuthung, dass es sich im vorliegenden Falle nicht nur um zufällige Härtungsverschiedenheiten oder Aehnliches, sondern vielleicht um pathologische. Zustände handeln könnte.

Im obersten Cervicalmark erstreckten sich die blass gebliebenen, graugelben Felder auf die Peripherie der Hinterstränge und die hintersten Partien der Seitenstränge in nächster Nähe der hinteren Wurzeln. (Fig. 7a.)

$\mathrm{Zu}$ beiden Seiten des Eintritts der hinteren Wurzeln waren sie am schmälsten; an der Grenze zwischen Goll'schen und Burdach'schen Strängen wurden sie breiter und ragten zugleich spornförmig nach innen, um sich in der Medianlinie nahe der hinteren Commissur zu treffen. Auch dem Sulcus longitudinal. post. entsprechend ragte ein schmaler grauweisser Strich zwischen die beiderseitigen Goll'schen Stränge hinein.

An zahlreichen Stufenschnitten durch die Cervicalanschwellung und des Dorsalmark liess sich erkennen, dass mit nur geringer Abweichung in Form und Ausdehnung dieselben Gebiete des Rückenmarks die abnorme Verfärbung zeigten. In der Mitte der Cervicalanschwellung hatte die blassgraue Färbung ihre grösste Ausdehnung dem hinteren Abschnitt der Goll'schen Stränge entsprechend. Am unteren Abschnitt der Cervicalanschwellung war von den Goll'schen Strängen jederseits nur ein schmaler Streif $\mathbf{z}$ beiden Seiten der Medianlinie dunkel gefärbt, das Uebrige, ebenso wie die periphere Zone der Burdach'schen Stränge, grauweiss. Im oberen Dorsalmark rückten die grauweissen Felder immer weiter nach aussen an die Hinterhörner der grauen Substanz heran, während die Goll'schen Stränge, mit Ausnahme einer schmalen Randzone, wieder normale Färbung annahmen. Im unteren Dorsalmark, ebenso wie im obersten Theile der Lendenanschwellung, war nur noch ein schmaler Saum zwischen den hinteren Wurzeln an der Peripherie der Hinterstränge entfärbt geblieben.

An tieferen Stufen der Lendenanschwellung von der Cauda equina war mit freiem Auge nichts Abnormes mehr nachweisbar.

Trotzdem zeigten sich aber bei der mikroskopischen Untersuchung auch an diesen Stellen Veränderungen.

Die sämmtlichen Gefässe des Conus terminalis, der Pia mater und der Wurzeln sind strotzend mit Blut gefüllt; ihre Wandungen sind kaum verändert, die Intima der Arterien vielleicht etwas verdickt. 
Der Conus terminalis selbst ist unverändert; weder die graue Substanz, noch die Ganglienzellen und die weisse Substanz bieten Veränderungen dar, nur die Substantia gelatinosa centralis und die gelatinöse Rindenschicht erscheinen ziemlich mächtig. Ein eigentlicher Central canal ist in der ganzen Länge des Rückenmarks nicht vorhanden, wenigstens kein Lumen eines solchen, nur eine Ansammlung von grösseren und kleineren Ependymzellenhaufen, welche allerdings einen ansehnlichen Raum einnehmen und einen nicht unerheblichen Theil der hinteren Commissur beanspruchen.

Die Pia mater ist nicht verdickt, auch nicht zellreicher als gewöhnlich.

Die Wurzeln zeigen ein verschiedenes Verhalten: die vorderen Wurzeln bieten auf Querschnitten ein vollkommen normales und regelmässiges Bild dar, abgesehen von der Hyperämie ihrer Gefässe. Die hinteren Wurzeln dagegen sind auffallend reich an schmalen Fasern und bieten auch sonst eine unregelmässige Zeichnung dar, als grössere und kleinere Gebiete des Querschnitts sclerosirt und ganz frei von Fasern sind und an zahlreichen Fasern Degenerationserscheinungen sowohl an den Axencylindern, als an den Markhtillen zu beobachten sind. In einigen wenigen Wurzeln sind grössere Segmente des Querschnitts sclerosirt, bezw. degenerirt. Viele der dinteren Wurzeln erscheinen auch im Ganzen ausserordentlich schmal und faserarm.

An höher oben gelegenen Stufen, d. h. durch das ganze Rückenmark hindurch verbalten sich die graue Substanz und die Ganglienzellen vollkommen normal. Der Centralcanal ist ersetzt durch einen Ependymfaden, welcher sich an allen Querschnitten aus beliebiger Höhe in derselben Weise darstellt, nämlich als eine Anhäufung von Ependymzellengruppen, welche ohne einen innigeren Zusammenhang in der etwas zerklufteten Substantia gelat. central. lagern und verhältnissmässig viel Raum einnehmen (vgl. Burresi, Semmola, Tizzoni l. c. l. c.).

Die weisse Substanz der Vorderstränge ist überall normal, auch diejenige der Seitenstränge bietet nur Veränderungen dar an den Austrittsstellen der hinteren Wurzeln, wo schon mit freiem Auge eine abnorme Graufärbung auffiel. Dasselbe ist der c'all bei der weissen Substanz der Hinterstränge.

An den Carminpräparaten lassen sich dieselben bereits beschriebenen und in Fig. 6 abgebildeten Felder, welche schon am ungefärbten, aber gehärteten Ruckenmark erkennbar waren, als dunkler tingirte Stellen mit freiem Ange wiedererkennen, obschon dann die Abgrenzung gegen die Nachbarschaft - wahrscheinlich wegen der Dünnheit des Schnittes nicht mehr so scharf und deutlich hervortritt, wie an den Ruckenmarkssegmenten (die nach Weigert's Methode behandelnden Schnitte zeigen mit freiem Auge keine Veränderung). Unter dem Mikroskop erscheint an diesen Stellen die Glia verbreitert, die Lücken zwischen denselben kleiner, viele Fasern ausgefallen. An der Peripherie dieser dunkleren Stellen erscheint das Gewebe wie rareficirt, die Nervenfasern stehen weiter aus einander, einige Axencylinder sind gequollen, andere ziemlich schmal und excentrisch gelegen, wieder andere ganz fehlend. Sehr deutlich sind diese Veränderungen keineswegs ausgesprochen, und es lässt sich unter dem Mikroskop sehr schwer die Grenze finden, wo wieder ganz normale Ver. 
Veränder. des sympath. u. cerebrospinal. Nervensyst. b. Addison'scher Krankh. 289

hăltnisse sind, resp. wo die ersten pathologischen Veränderungen beginnen. Ich wage es deswegen auch nicht, diese Veränderungen oder Unregelmässigkeiten in den Hintersträngen als eine beginnende Systemerkrankung anzusprechen, sondern beschränke mich darauf, dieselben zu erwähnen und anzudeuten, dass an den betreffenden Stellen des Rückenmarks nicht ganz normale Verhältnisse herrschen.

An allen Segmenten des Rückenmarks konnte ich Degenerationserscheinungen an den hinteren $W$ urzeln constatiren, ähnlich wie ich sie bei der Cauda equina erwähnte. $O b$ aber ein graduelles $\mathrm{Zu}$-oder $\mathrm{Ab}$ nehmen der Degeneration und der Sclerosirung nach oben oder unten stattfindet, bin ich nicht in der Lage bestimmt zu entscheiden, weil die Veränderungen nirgends höhere Grade erreicht haben. Die vorderen Wurzeln waren durchgehends normal, einige unregelmässige Färbungen, welche ja überall vorkommen können, abgerechnet.

In den oberen Abschnitten des Rückenmarks waren in der Pia mater ab und za Pigmentablagerungen geringen Grades zu erkennen, sonst aber nichts Abnormes.

Um kurz zu resumiren, ergab also die Untersuchung des Rückenmarks zunächst Degenerationserscheinungen an den hinteren Wurzeln, welche aber nicht den Grad erreichten, wie sich nach den Befunden an den Spinalganglien erwarten liess. Ferner zeigte sich in einer von unten nach oben zunehmenden Weise eine makroskopisch durch grauweisse Verfärbung, mikroskopisch durch geringgradige Sclerosirung (mit zweifelhaftem Faserschwund) gekennzeichnete Veränderung in der weissen Substanz der Hinterstränge, welche auf ganz bestimmte Regionen localisirt ist und im Allgemeinen den Eintrittsstellen und dem Verlanfe der centripedalen sensiblen Fasern im Rückenmark entspricht.

$\mathrm{Ob}$ dem nicht gerade ungewöhnlichen Verhalten des Centralcanals ein grösserer Werth in diesem Falle zuzuschreiben ist, will ich dahingestellt sein lassen.

\section{Die peripheren Nerven.}

Von den peripheren Nerven habe ich den Nervus vagus, den Cruralis, Ischiadicus und als rein sensiblen Nerv den Nerv. cutaneus cruralis medius untersucht.

Makroskopisch war an diesen Nerven nichts Besonderes aufgefallen.

Von den mikroskopischen Veränderungen beanspruchen, wegen der Dignität des Nerven, das grösste Interesse diejenigen des Vagus. Das Perineurium erscheint nicht erheblich verdickt, doch zeigt dasselbe an Präparaten, welche mit kernfärbenden Mitteln behandelt wurden, namentlich bei Doppeltfärbungen mit Hämatoxylin und Eosin, zwei deutliche Schichten: eine äussere, fibröse und zellarme, und eine innere zellreiche Schicht, welche ausser dem Zellreichthum noch eine beträchtliche Infiltration mit Rundzellen darbietet. Die letztere ist nicht überall gleich, sondern zeigt fleckweise graduelle Unterschiede und ist in der Nähe von Gefässen am deutlichsten.

Auch im Innern des Nervs ist in der Umgebung der Gefässe Bindegewebsvermehrung und Rundzelleninfiltration nachweisbar, jedoch nicht in dem Maasse, wie es beim Sympathicus der Fall war. Eine Kernwuche- 
rung ist auch an anderen Stellen des Vagus nicht ganz in Abrede zu stellen, trotz des Einwandes, dass Kernwucherungen namentlich an Querschnitten sehr häufig dadurch vorgetäuscht werden, dass zahlreiche Nervenfasern geschwunden und das präexistente Gewebe hernach näher zusammengezogen erscheint. Die Gefässe zeigen verdickte Wandungen, namentlich die kleineren Arterien des Perineurium; einzelne derselben sind obliterirt.

An den nach Weigert gefärbten Präparaten fällt zuerst der enorme Reichthum an schmalen markhaltigen Fasern in die Augen. Ein beträchtliches Quantum von Fasern ist ausgefallen, und von den erhalten gebliebenen, sowohl breiten als schmalen, sind ausserordentlich viele in Degeneration begriffen. Quellung, Zerklüftung und scholliger Zerfall des Marks tritt überall zu Tage.

Am auffälligsten ist der Faserschwund an den Querschnitten des Vagus. Breite und schmale Fasern sind zu Bündeln vereinigt; eine grosse Zahl dieser Btindel sind an Weigert-Präparaten von brauner Farbe, da und dort nur deutet ein oft unregelmässig geformter schwarzer Fleck oder ein schwarzer Punkt auf das Vorhandensein einer markhaltigen Faser hin. Die Carminpräparate, welehe immer zum Vergleiche herangezogen wurden, entsprachen diesem Befunde.

\section{Nervus cruralis.}

Auch der Stamm des Nervus cruralis ist von pathologischen Veränderungen nicht freigeblieben: das Perineurium ist verdickt, zweischichtig. Die innere Schicht ist reich an spindelförmigen und rundlichen Zellen, das Endoneurium ebenfalls. Die einzelnen Bündel stehen sehr weit aus einander und zeigen auf Längs- und Querschnitten Degenerationserscheinungen und Schwund von Nervenfasern. Auch hier sind die Nervenbündel wieder übermässig reich an schmalen markhaltigen Fasern.

Die Degenerationserscheinungen an den Nervenfasern sind, obwohl zweifellos vorhanden und deutlich nachweisbar, bei Weitem nicht so hochgradig, wie am Vagus und Sympathicus. Gewöhnlich besteht an den Fasern des Cruralis varieöse Auftreibung abwechselnd mit Verdünnung der Nervenfasern, ausserdem Zerklüftung und scholliger Zerfall des Marks. Besonders sind es die schmalen Fasern, welche diese Veränderungen zeigen, während die breiten weniger betheiligt zu sein scheinen.

$\mathrm{Ob}$ es sich um Fasern mit bestimmter Function im Cruralis handelt, welche vorwiegend degenerirt sind, lässt sich natürlich schwer entscheiden. Einen Fingerzeig bietet in dieser Hinsicht vielleicht die Untersuchung eines rein sensiblen Astes vom Cruralis: des

Nervas cutaneus femoris medius.

Dieser Ast weist die Degenerationserseheinungen und einen Ausfall von Nervenfasern in viel beträchtlicherem Maasse auf, als der Cruralisstamm. Der Gehalt an schmalen markhaltigen Fasern ist hier wieder so gross, dass ihre Zahl schätzungsweise die Hälfte sämmtlicher Fasern beträgt. Auf Längs- und Querschnitten ist ersichtlich, dass viele Fasern fehlen; von den noch vorhandenen zeigen auffallend viele die Zeichen der Degeneration von Axencylinder und Markscheide, ausserdem Kernwuche- 
Verănder. des sympath. u. cerebrospinal. Nervensyst. b. Addison'scher Krankh. 291

rung. Perineurium und Endoneurium verhalten sich wie am Cruralisstamm, ebenso die Gefässe.

Am Nerv. ischiadicus und medianus ist der Befund ganz derselbe wie am Cruralis.

\section{Die Muskeln.}

Von den Muskeln habe ich leider nur den Musc. semitendinosus zur Untersuchung verwendet. Dabei habe ich kaum wesentliche Abweichungen von der Norm constatiren können. Die Querstreifung war auf Längsschnitten vollkommen schön und deutlich erhalten; die einzelnen Fasern zeigten dieselbe Breite, die Sarkolemmaschlänche waren kernreicher als gewöhnlich. Auch zwischen den einzelnen Muskelfasern war ein geringer Grad von Bindegewebswucherung zu erkennen. Der Befund an den Querschnitten verhielt sich dementsprechend: grösserer Reichthum an Kernen mit Andeutungen von interstitieller Bindegewebswucherung bei vollkommen normalen and gleichgrossen Muskelfasern.

Herz und Gefässe.

Die Musculatur des Herzens war an beiden Ventrikeln bei mittelweiter Höhlung der letzteren von mittlerer Dicke und rothbrauner Farbe.

Mikroskopisch ist am Myocard eine interstitielle, von den Gefässen ansgehende Bindegewebswucherung ganz evident. Sowohl zellreicheres, junges Bindegewebe, als auch derbes, fibröses durchsetzt das Myocard nach allen Richtungen. Die Muskelzellen selbst erscheinen auf Längsschnitten, d. h. da, wo sie in der Längsrichtung getroffen sind, schmal und dünn; auf Querschnitten sind sie dementsprechend kleiner, als der Norm entspricht. Die Querstreifung ist vielfach wohlerhalten, aber nicht mehr überall nachweisbar. In zahlreichen Muskelzellen finden sich in der Umgebung der Kerne Anhäufungen von bräunlichen Pigmentkörnern.

Am Pericard und Endocard ist nichts Abnormes nachweisbar.

Der mikroskopische Befund am Herzen entspricht demnach der Diagnose: Fibröse Myocarditis mit brauner Atrophie. - Bei der Befundsbeschreibung am Sympathicus und an den Spinalganglien hat mehrfach eine Verdickung der Gefässwände, namentlich der Intima, mit hyaliner Degeneration Erwäbnung gefunden. Am Rückenmark hatte diese Veränderung nur geringe Grade erreicht, auch an den iubrigen Organen, wie Leber, Lunge, Nieren, Milz und Lymphdrüsen, war sie nicht besonders auffällig. Dagegen zeigen wieder grössere Gefässstämme, wie z. B. die Carotiden, in sehr deutlicher Weise, wenn auch nicht hochgradig, die Zeichen der Endarteritis fibrosa (obliterans).

\section{Die übrigen Organe.}

Leber, Lunge, Milz und Nieren zeigten bei der mikroskopischen Untersuchung nichts Anderes, als was schon im Sectionsprotokoll über dieselben gesagt wurde. Ein geringer Grad interstitieller Bindegewebsvermehrung war wohl überall nachweisbar, doch dürfte dieser Befund kaum eine besondere pathologische Bedeutung haben. Intensivere Grade der Gefässveränderung habe ich in den genannten Organen nicht nach- 
weisen können, und, was ich besonders hervorheben möchte, nirgends hatten in den betreffenden Organen Pigmentablagerungen stattgefunden.

In dieser Hinsicht erscheint mir auch der Befund an den Lymph$\mathrm{dr}$ ii sen besonders erwähnenswerth, dass nirgends, auch nicht in den den Nebennieren zunächst gelegenen Lymphdrüsen $\mathrm{mehr}$ Pigment abgelagert war, als man dies gewöhnlich findet. Es muss daraus geschlossen werden, dass eine Circulation von Pigment im Blute oder in der Lymphe beider Addison'schen Krankheit nichtstattfindet.

Haut und Wangenschleimhaut.

Zur mikroskopischen Untersuchung habe ich pigmentirte Wangenschleimhaut, Hautstückchen vom Halse, von den Ellbogenbeugen, vom Scrotum und von den Kniekehlen verwendet.

Der histologische Befund an allen diesen Theilen war derselbe und ist in ubereinstimmender Weise schon so vielfach beschrieben worden, dass ich wohl darauf verzichten kann, eine detaillirte Beschreibung hier zu wiederholen. Ich verweise daher nur auf die Angaben von Virchow l. c., v. Recklinghausen ${ }^{1}$ ), Averbeck ${ }^{2}$ ), Nothnagel ${ }^{3}$ ), Rieh14), Ehrmann ${ }^{5}$ ), Demiéville ${ }^{6}$ ), v. Kahlden $)^{\text {) }}$. A. und beschränke mich auf die Bemerkung, dass ich entgegen der Ansicht vieler Autoren den Eindruck gewonnen habe, dass sich zwischen den Zellen der Epidermis in den Lymphspalten und Saftcanälchen auch freies, nicht in Zellen eingeschlossenes Pigment vorfindet.

\section{Fall.}

Nikolaus Kopp, 44jähriger Stuhlflechter von Rastatt, kinderlos verheirathet, ist von Seiten seines Vaters hereditär tuberculös belastet, war jedoch, abgesehen von einer Pneumonie im Jahre 1872, vor dem hier in Betracht kommenden Leiden niemals ernstlich krank. Excesse in Baccho et Venere hat er nicht begangen. Nach einer starken Durchkältung bei der Arbeit - 6 Stunden bis zum Nabel im Wasser stehend und Schilf schneidend - bemerkte Patient im October 1888 das Auftreten gelbbrauner Flecke auf Brust und Rücken, welche beim Schwitzen juckten und seiner Beschreibung nach mit den jetzt noch nachweisbaren Flecken von Pityriasis versicolor identisch gewesen sind.

Das subjective Wohlbefinden wurde erst seit Mitte April 1889 beeinträchtigt; es stellten sich damals dyspeptische Beschwerden ein, Gefuhl

1) Handbuch d. allgem. Pathologie u. Berliner klin, Wochenschrift. I. Nr. 7.

2) Die Addison'sche Krankheit. Erlangen 1869.

3) Zur Pathologie des Morbus Addisonii. Zeitschr. f. klin. Med. 1885. IX.

4) Zur Pathologie des Morbus Addisoni. Zeitschr. f. klin. Med, 1886. X.

5) Sitzungsberichte der Wiener Akad. d. Wissenschaften. 1881. Allg. Wiener med. Zeitung. 1884. Nr. $29 . !$

6) Deux cas de maladie d'Addison. Revue méd. de la Suisse Romande.

7) Beiträge zur pathol. Anatomie der Addison'schen Krankheit. Virchow's Archiv. 1888. Bd, CXIV. 
von Druckim Epigastrium vorzüglich nach dem Essen. Auch mechanischer Druck von aussen, wie z. B. das Tragen des Leibriemens, rief öfters recht peinigende, spannende Schmerzen quer ib er dem Epi gastrium und den seitlichen Theilen des Leibes hervor. Zeitweise stellte sich Durchfall ein, 6-8 dünne, gelbliche Stüle am Tage, abwechselnd mit Verstopfung. Dabei wurde der Appetit schlechter, viel Durst stellte sich ein, Erbrechen trat nie auf.

$\mathrm{Zu}$ dieser Zeit bemerkte der Patient, der früher keinerlei abnorme Pigmentirung oder ungewöhnlich dunklen Teint gehabt hatte, dass sein Hals anfing dnnkelgefärbt zu werden, eine Verfärbung, die an Intensität immer zunahm und sich dabei auf Gesicht, Achselhöhlen, Ellbogenbengen, Brustwarzen, Bauch und Geschlechtstheile weiter ausdehnte.

Allmählich wurde das Allgemeinbefinden schlechter, die Kräfte nahmen ab, namentlich fühlte sich Patient nach 2-3 stündiger Arbeit oft schon so $m \ddot{u} d e$, dass er aufhören und sich hinlegen musste, während er früher 8-10 Stunden za arbeiten gewohnt war. Gleichzeitig nahm auch der Geschlechtstrieb ab, die sexuelle Kraft erlosch.

Kopfschmerz, Schwindel, Ohrensausen, Ohnmachten und sonstige cerebrale Erscheinungen fehlten, auch die Intelligenz war in keiner Weise gestört. Nachtschweisse bestehen seit längerer Zeit, ebenso ab und zu Husten mit geringem Auswurf.

Status am 28. Juni 1889 bei der Aufnahme ins Krankenhaus: $\mathrm{Pa}$ tient mittelgross, von kräftiger Statur und ebensolcher Musculatur, Fettpolster sehr mässig.

Die Haut des Gesichts ist der Stirn, den Wangen und dem Kinn entsprechend braun, bronceähnlich pigmentirt; am Halse nimmt die Fär bung an Intensität zu, geht ins Grauschwärzliche über. Dabei zeigt die Haut eine sehr starke Furchung, ohne jedoch eigentlich verdickt oder infiltrirt $\mathrm{zu}$ sein.

Die ganze Brust ist mehr gleichmässig granbraun pigmentirt, doch sind anf der Mitte des Sternum einige hellere Flecke eingestreut, während die Brustwarzen schwarzbraun, glänzend erscheinen. Nach unten wird die Pigmentirung etwas heller, mehr fleckig.

Um den Bauch herum zieht da, wo der Leibgürtel zu liegen pflegte, ein braunschwarzer Ring. Die Linea alba, die ganze Unterbauchgegend sind intensiv braun, beide Leistenbeugen und die Genitalien nahezu schwarz, ebenso die Analfurche.

Auf dem Rücken sind handtellergrosse Pigmentflecke von braungelber Farbe symmetrisch angeordnet. $\mathrm{Z}$ wischen diesen grösseren sind zahlreiche kleinere Flecke von mehr graubräunlicher Farbe, welche um ein Geringes das Nivean überragen und an der Oberfläche Abschnppung und einzelne Kratzeffecte zeigen. Aehnliche Flecke finden sich auch auf den Schultern und zwischen den geschilderten Pigmentirungen auf der Brust zerstreut.

In der Lendengegend sind nur vereinzelte bräunliche Flecke, während die Haut über dem Kreazbein wieder gleichmässig braun und bronceähnlich pigmentirt ist.

Beide Achselhöhlen sind nahezu schwarz pigmentirt; die Ellbogenbeugen beiderseits zeigen grössere, confluente und einige kleinere braune Flecke. 
Die Streckseite der Oberarme ist frei von Pigment, dagegen zieht an der Innenseite beider Oberarme, dem inneren Rande des Biceps entlang, von der Achselhöhle bis zur Ellibogenbeuge ein circa $3 \mathrm{Cm}$. breiter, ans linsen- bis zwanzigpfennigstickkgrossen Flecken bestehender brauner Streifen herab. Diese Flecken sind nirgends uber das Niveau erhaben und zeigen weder Abschuppung noch Kratzeffecte.

Vorderarme und Handrücken sind kupferbraun gefärbt, die Nägel auffallend hell. Handteller nicht pigmentirt.

An den Unterextremitäten zeigen nur die Innenflächen der Oberschenkel schwache Pigmentirung; in beiden Kniebeugen ist die letztere wieder intensiver.

Die Schleimhant des Mundes zeigt den Lippen und beiderseits den Wangen entsprechend linsengrosse und grössere, durch Confluenz kleinerer entstandene braune Flecke. Ekchymosen oder sonstige Hämorrhagien sind auf der Mundschleimhaut nirgends nachweisbar.

Bei der mikroskopischen Untersuchung der Schüppchen oder abgekratzter kleienförmiger Partikelchen von den beschriebenen graugelben, helleren Flecken des Rïckens und der Brust zeigen sich bei Aufhellung der Präparate mit Kalilauge und Glycerin in sehr schöner Weise die kurz verzweigten Mycelien und zwischen denselben die nester- oder traubenförmigen Herde der Sporen von Mikrosporon furfur.

An den braunpigmentirten Stellen des Gesichts, der Arme, Achselhöhlen, des Bauches, der Leistenbeugen u. s. w. fehlen diese Pilze in abgeschabten Epidermisschüppchen gänzlich.

K op f: Pupillen beiderseits gleich weit, reagiren gut. Conjunctivae und Sclerae normal, namentlich sind die letzteren rein weiss und stechen scharf $a b$ von dem braunpigmentirten Gesichte.

Zunge nicht belegt. Sprache normal. Halsorgane nicht verändert.

Die Lungen sind in allen Grenzen etwas vergrössert, die Athemgeränsche sind normal, links hinten oben etwas verlängertes Exspirium, keine dentliche Dämpfung.

Herzgrenzen normal, Töne rein, Puls mässig gespannt, 82.

Abd omen im Epigastrium und beiden Weichen druckempfindlich, besonders links. Im Mesogastrium, dem Verlauf des Colon transversum entsprechend, aber jedenfalls hinter diesem gelegen, fühlt man einen grossen, höckerigen, harten, nicht verschieblichen Tumor dicht vor der Wirbelsäule, welcher sich etwas mehr nach links hinüber erstreckt, als nach rechts, und etwa bis zum Nabel herabreicht. Nach oben ist er durch eine Zone tympanitischen Schalles von der Leber deutlich getrennt. Der Tumor ist sehr druckempfindlich, genaue Palpation und Messung deshalb sehr erschwert und unsicher.

In der Gegend des Fundus ventriculi ist Plätsehern nachweisbar.

In der Unterbauchgegend ist Fluctuation nachzuweisen, jedoch keine deutliche, den Platz wechselnde Dämpfung.

Die beiderseitigen supraclavicularen Lymphdrüsen sind intumescirt, rechts stärker als links. farbstoff.

Urin saner, klar, 1020, ohne Albumen, ohne Zucker, ohne Gallen- 
Verănder. des sympath. u. cerebrospinal. Nervensyst. b. Addison'scher Krankh. 295

Die $\mathrm{Milz}$ ist nicht palpabel; auch von den $\mathrm{Nier}$ en ist nichts zu fülen, jedoch zeigt sich bei der Nierenpercussion in der Bauchlage, dass die den Nieren zugeschriebene Dämpfung rechterseits bis zu $9 \mathrm{Cm}$., linkerseits $10 \mathrm{Cm}$. breit ist.

Gelegentlich einer klinischen Vorstellung des Patienten am 10. Juli wurde unter Berücksicbtigung der Hautpigmentirung, der gastrointestinalen Störungen, der Muskelschwäche, des fortschreitenden Kräfteverfalls, endlich der abdominellen Tumoren, deren Sitz in die retroperitonealen Lymphdrüsen verlegt wurde, von Herrn Professor Erb die Diagnose auf Morbus Addisoniigestellt. Man nahm an, dass die genannten Tumoren die Nebennieren - wahrscheinlich vorwiegend die linke Nebenniere - in Mitleidenschaft gezogen und die grossen Ganglien des Bauchsympathicus betroffen hätten.

Welcher Natur die Tumoren waren, blieb vorerst noch offene Frage. Tuberculöse Lymphome waren wegen der aus der Anamnese ersichtlichen hereditären Belastung, wegen der leichten, ab und zu beobachteten Fieberbewegungen und wegen des Befundes an der linken Lungenspitze nicht ganz auszuschliessen. Indessen liess das während des Spitalaufenthaltes einige Male beobachtete Erbrechen, der Mangel freier Salzsäure im Erbrochenen, der rasch sich steigernde Kräfteverfall, die Annahme eines Carcinoms, welches seinen Ausgang vom Magen genommen haben könnte, nicht von der Hand weisen.

Dementsprechend wurde die Therapie eingerichtet: der Patient erhielt Condurango als Wein und Decoct, Liq. Kal. arsenic. und wurde streng diätetisch ernährt und gepflegt.

Im Angust verliess Patient in etwas gebessertem Zustande das Krankenhaus, kam aber nach wenigen Wochen erheblich heruntergekommen zum zweiten Mal zur Aufnahme.

Aus dem Krankheitsverlaufe während des zweiten Spitalaufenthaltes verdient hervorgehoben 20 werden, dass die gastrischen Symptome immer mehr in den Vordergrund traten: d as Erbrechen wurde häufiger, besonders nach der Nahrungsaufnahme, die üblichen Reactionen zum Nachweis freier Salzsäure im Magensafte gaben constant negative Resultate.

Unter fortwährender Grössenzunahme der Tumoren in der Bauchhöhle verbreitete sich die bronceähnliche Pigmentirung der Haut auf grössere Bezirke und nahm zugleich an Intensität zu. Nach öfters wiederholten Abseifungen der früher beschriebenen, mehr graugelben Flecken auf der Haut der Brust und des Räckens verschwanden die Pilzcolonien des Mikrosporon furfur, während die Addison'sche Pigmentirung nur um so reiner wurde und weitere Fortschritte zeigte.

$\mathrm{Ab}$ und zu klagte Patient über spannende und bohrende Schmerzen in der Brust, unter dem Sternum, welche durch Injection geringer Dosen von Morphium gemildert werden mussten. Auch Chloralamid wurde als Schlafmittel verabreicht.

Mitte $\mathrm{October}$ trat unter Vergrösserung der Leber zunächst ic terische Verfärbung des Urins auf, welcher binnen 2-3 Tagen intensiver Icteras der Haut und der sichtbaren Schleimhänte folgte. Der untere Leberrand trat bis zu 3 Querfingerbreite unter den Rippen- 
bogen; die Gallenblase wurde an der entsprechenden Stelle als halbkugeliger Tumor von $6 \mathrm{Cm}$. Breite, $7 \mathrm{Cm}$. Länge unterhalb des Leberrandes fühlbar. Die Faeces wurden acholisch und nur unter Beihtilfe reichlicher Einläufe entleert.

Die letzten 3 Wochen seines Lebens lag Patient in ganz apathischem, somnolentem Zustande zu Bett. Die Nahrungsaufnahme war sehr erschwert, das Erbrechen häufig. Durch den intensiven Icterus, zusammen mit der Addison'schen Pigmentirung, war das Aussehen ein hochgradig entstelltes; am Halse und den sonst als hochgradig pigmentirt genannten Stellen hatte die Haut Färbung und Glanz alter Bronce angenommen.

Die Blutkörperchenzählung ergab am 27. October $2^{1 / 2}$ Millionen rother, relative Vermehrung der weissen Blutkörperchen, freies Pigment im Blute fehlte. Hämoglobinbestimmung war wegen des reichlichen Gallenfarbstoffes erschwert, doch schien der Hämoglobingehalt normal zu sein.

Im Urin hatte Albumen constant gefehlt; auch die v. Jaksch'sche Reaction auf Melanurie fiel negativ aus, ebenso die Acetonreaction.

Exitus am 30. October 1889.

Klinische Diagnose: Carcinoma ventriculi. Metastasen in der Leber, in den retroperitonealen und mediastinalen Lymphdrüsen und den Nebennieren, Resorptions(Staungs-)icterus. Mor bus Addis onii.

Die Section wurde am 31. October 1889 von Herrn Geh.-Rath A r nold vorgenommen. Dem Sectionsprotokolle entnehme ich auszugsweise:

Ausser der (bereits ausführlich) beschriebenen Färbung und Pigmentirung der Haut zeigt auch die Schleimhaut der Mundhöhle gleichfalls braune Flecke, besonders stark auf der rechten Seite, der Krone der Backzähne entsprechend.

Hinter dem Manubrium sterni ist eine Geschwulstmasse, welche, am Jugulum beginnend, daselbst eine ziemliche Breite besitzt, namentlich in die linke Pleurahöhle prominirt und daselbst sich nach unten bis zar Umschlagsstelle des Herzbentels ausdehnt.

In der Herzbentelhöhle intensiv icterisch gefärbte, schwach trübe Flüssigkeit. Das viscerale Blatt des Herzbentels ist sehr arm an Fett, das Fett durch schleimige Massen ersetzt.

An Hinterfläche und Basis des rechten Ventrikels im Pericard ganz kleine, weisse, ziemlich derbe Knötchen, ebensolche vereinzelt an der Insertionsstelle der Arteria pulmonalis. Die Arteria pulmonalis selbst und die Aorta an ihrer Vorderfläche mit ebensolchen Knötchen besetzt. Das Zellgewebe daselbst mehr gleichmässig infiltrirt; auch das Pericard. parietale zeigt an dieser Stelle Infiltration mit solchen Knötchen. Das Herz ist kaum mittlerer Grösse und enthält in allen seinen Abtheilungen dunkles, schmieriges, klumpig geronnenes Blut. Die im Mediastinum gelegene Tumorenmasse umfasst die Aorta, ebenso die Abgangsstelle der linken Carotis.

In Anschluss an diesen Tumor befinden sich beiderseits uber der Clavicula nussgrosse Tumoren (infiltrirte Lymphdrüsen). Der Nerv. vagus verläuft links durch die mediastinale Tumormasse hindurch und ist von derselben allseitig umschlossen. Der linke Sympathicus zieht an der 
Veränder. des sympath. u. cerebrospinal. Nervensyst. b. Addison'scher Krankh. 297

hinteren Fläche des Tumors nach unten, das untere Halsganglion erscheint in infiltrirtes Gewebe eingebettet.

Die Bauchdecken sind mässig gespannt. In der Banchhöhle ist eine geringe Menge icterischer, klarer Flüssigkeit; die Dünndarmschlingen nehmen nur die untere Banchbälfte ein.

Das Colon transversum ist sehr lang, sehr ausgedehnt und mit Gasen und Koth gefüllt, der Magen ist im Fundustheil weiter, die Magenmitte und der Pförtnertheil sind enger. Hinter dem Magen fühlt man eine ausgedehnte Geschwulstmasse, welche links von der Wirbelsäule dicht unterhalb des Zwerchfells beginnt, sich etwas weiter unten über die Wirbelsäule hinwegzieht und beiderseits und vor der Wirbelsäule sich abwärts bis unterhalb der Nieren erstreckt. - Die Leber steht etwas höher. Die Gallenblase ubberragt den unteren Leberrand um $71 / 2 \mathrm{Cm}$. und ist stark erweitert. Sie enthält eine ganz enorme Menge dickflüssigen, grünen Secretes und misst vom Fundus bis zum höchsten Punkt des Halses 12 Cm.; der grösste Durchmesser von vorn nach hinten ist $61 / 2 \mathrm{Cm}$.

Am Hilus der vergrösserten Leber finden sich einige markig infiltrirte Lymphdrüsen, in der Pfortader ein agonales Gerinnsel. Ductus choledochus ganz beträchtlich dilatirt; auch die Ductus hepatici sind onorm erweitert und mit dunkelgrüner Galle angefüllt.

Leberkapsel, besonders über dem rechten Leberlappen, sehnig verdickt; unter der Kapsel befinden sich sowohl im rechten als im linken Leberlappen grössere und kleinere markige Einlagerungen. Auf dem Durchschnitt sind im Gewebe grössere und kleinere markige Knoten zerstreut.

Das Lebergewebe stark icterisch; an zahlreichen Stellen sind auf dem Querschnitt stark erweiterte Gallengänge mit verdickter Wand und grünlich imbibirter Umgebung. Im linken Leberlappen sind diese Veränderungen verhältnissmässig stärker ausgesprochen, als im rechten.

Im kleinen Netz und im Mesenterium sind theils circumscripte, theils zu einem grösseren Tumor confluirte Geschwulstmassen, welche vor der Aorta liegen, aber verschieblich sind.

Chylusgefässe im Mesenterium mit markiger Masse erfüllt; Serosa des Duodenum mit ebensolchen Massen völlig injicirt.

Milz etwas vergrössert, fest mit dem $Z$ werchfell vierwachsen, Kapsel fibrös. Milzgewebe blutreich, etwas derber.

Im Magen findet sich, neben der Insertionsstelle des Oesophagus, entsprechend der kleinen Curvatur, in der hinteren Magenwand eine ziemlich grosse Geschwulst von ovalärer Form, deren grösster Längsdurchmesser $12 \mathrm{Cm}$., deren grösster Breitendurchmesser $8 \mathrm{Cm}$. beträgt. Die gegen das Mageninnere gerichtete Fläche derselben ist in der ganzen Ausdehnung ulcerirt.

Der Pförtnertheil des Magens ist normal; auch im Duodenum ist normaler Befund. Dagegen ist der duodenale Theil des Duct. choledochus durch eine rundliche Geschwulstmasse, welche in den letzteren vorspringt, gänzlich comprimirt. Der Pankreaskopf ist vergrössert und derb.

Die Geschwulst des Magens ist nach aussen von Serosa überzogen, doch sind die retrogastrischen Lymphdrúsen an dieser Stelle mit der Oberfläche des Tumors verwachsen, stark vergrössert und setzen sich nach

Deutsche Zeitsehr. f. Nervenheilkande. II. Bd. 
links hin und hinten in eine Geschwulstmasse fort, welche mit der vergrösserten linken Nebenniere in Zusammenhang steht. Diese linke Nebenniere stellt einen ovalären Tumor dar, dessen Längsdurchmesser $5^{1} / 2$, dessen grösster Breitendurchmesser $3 \mathbf{C m}$, dessen Dicke $4 \mathrm{Cm}$. beträgt.

Die rechte Nebenniere zejgt normale Verhältnisse.

Beide Nieren sind von mittlerer Grösse, anscheinend unverändert.

Im Rectum viel grauweisser Koth; Schleimhaut unverändert; im ubrigen Darmtractus nichts Abnormes.

Die Präparation der Nervi sympathici, welche Herr Geheimrath Ar nold mir selbst übertragen hatte, ergab folgenden merkwürdigen Befund:

Der rechte Sympathicus zeigt vom oberen Halsganglion abwärts bis zur Abgangsstelle des rechten Nerv. splanchnicus major keine auffallenden Veränderungen; dagegen erscheinen sowohl der Grenzstrang des Sympathicus, als der Nerv. splanchnicus selbst von dieser Stelle ab gleichmässig verdickt und lassen sich nur bis zu der der Vorderfläche der Wirbelsäule fest auflagernden Geschwulstmasse herab präpariren, in welch' letztere sie sich verlieren. Das rechte Gangl. semilunare ist in diese Geschwulstmasse gänzlich eingebettet und nicht frei zu präpariren.

Im linksseitigen Sympathicus sind an verschiedenen Stellen augenfällige Veränderungen zu constatiren.

Das obere Halsganglion ist mächtig vergrössert und in eine spindel, förmige Geschwulst von Taubeneigrösse umgewandelt, deren Umfang $51 / 2 \mathrm{Cm}$., deren Länge $3,2 \mathrm{Cm}$. beträgt. Allmählich sich verjüngend, geht der Halssympathicus aus dieser Anschwellung hervor und setzt sich anscheinend unverändert bis zum unteren Halsganglion fort. Dieses ist in eine geschwulstartig infiltrirte Gewebemasse eingebettet, lässt aber selbst keine auffälligen Veränderungen erkennen.

Ein mittleres Halsganglion fehlt linkerseits; rechts ist dasselbe als kaum auffällige Auftreibung des Nervenstranges angedeutet.

Der linke Grenzstrang des Sympathicus lässt in der Brusthöhle keine wesentlichen Veränderungen erkennen, dagegen sind die beiden oberhalb der linken Nebenniere gelegenen Ganglien stark vergrössert, anscheinend markig infiltrirt, von derber Consistenz und zu flachen, unregelmässig gestalteten Tumoren umgewandelt.

Unterhalb dieser Ganglien verliert sich wiedernm der Grenzstrang und etwas höher oben der verdickte linksseitige Nerv. splanchnicus major, ebenso ein nach der Nebennierengeschwulst hinziehender Nervenstrang gänzlich in der vor und links von der Wirbelsäule gelegenen Tumormasse. Der Plexus coeliacus ist aus der letzteren wegen gänzlicher Verwachsung unmöglich herauszupräpariren.

In Gross- und Kleinhirn, ebenso wie in Medulla oblongata und Rückenmark sind makroskopische Veränderungen nirgends nachweisbar, ebensowenig in peripheren Nerven.

Dagegen lassen von den unteren Brust- und oberen Lenden-Intervertebralganglien die linksseitigen eine Vergrösserung gegen die rechtsseitigen erkennen und erscheinen gleichzeitig stärker pigmentirt.

Dem Sectionsprotokolle gemäss hat der pathologische Befund die klinische Diagnose Morb. Addisonii nicht nur bestätigt, sondern auch höchst 
Veränder. des sympath. u. cerebrospinal. Nervensyst. b. Addison'scher Krankh. 299

interessante, für die Lehre und Genese der Broncekrankheit vielleicht werthvolle anatomische Anhaltspunkte gegeben.

\section{Die Neubildung.}

Um zuerst das Grundleiden, den Tumor zu analysiren, so zeigt derselbe bei der mikroskopischen Untersuchung einen cellulären Charakter. Die Zellen bieten die Eigenschaften der Bindegewebszellen dar, zeigen aber in den Geschwulstmassen sehr deutliche alveoläre Anordnung. An geeigneten Schnitten oder Schnittstellen ist indessen 20 erkennen, dass die alveoläre Anordnung abhängig ist von der Gefässvertheilung, und in der That lassen sich auch sehr vielfache Beziehungen der Geschwulst zu den Gefässwänden, welche vermuthlich den Ausgangspunkt der Nenbildung darstellen, nachweisen. Es ist demvach die makroskopische Diagnose der Neubildung nach den Ergebnissen der histologischen Untersuchung dahin zu berichtigen, dass es sich nicht um ein Carcinom, sondern um ein alveoläres Sarkom (Angiosarkom) im vorliegenden Falle handelt.

Welcher Theil als primärer Erkrankungsherd anzusprechen ist, lässt sich natürlich bei dem vorgeschrittenen Stadium der Neubildung sehr schwer entscheiden. Jedenfalls ist weder der Magen, noch die linke Nebenniere der primär erkrankte Theil gewesen. Am wahrscheinlichsten ging von den retrogastrischen Lymphdrüsen die Geschwulstentwicklung aus.

\section{Die Nebennieren.}

Der Dignität der Nebennieren in der Frage über die Natur der Addison'schen Krankheit entsprechend, beginne ich die histologische Untersuchung mit diesen Organen.

Nach den Angaben des Sectionsberichtes hat sich bei der makroskopischen Besichtigung nur die linke Nebenniere als erkrankt erwiesen, während die rechte Nebenniere anscheinend normale Verbältnisse darbot.

An den Schnitten durch die linke Nebenniere zeigte sich, dass wesentlich in der Marksubstanz derselben die Neubildung ihren Sitz genommen hatte. Grössere und kleinere Geschwulstmetastasen durchsetzten die Nebenniere derart, dass von der Marksubstanz kaum mehr etwas intact geblieben war. Die Rindenschicht war dem gegenüber verhältnissmässig intact geblieben, nur da und dort zeigten sich kleinere Geschwulstherde, welche übrigens die Structur des Rindenparenchyms nur unbedeutend alterirten. Wo im Marke die Neubildungsherde eine betrăchtlichere Ausdehnung angenommen hatten, zeigten sich im Centrum theils eiterige, theils käsige Zerfallserscheinungen. Auch in der Peripherie solcher Herde war vielfach kleinzellige Infiltration mit beginnender Eiterbildung. Der grösste Theil des Marks der linken Nebenniere war auf diese Weise zerstört, während die Rinde verhältnissmässig nur wenig gelitten hatte.

Die rechte Nebenniere erschien mit freiem Auge betrachtet normal. An mikroskopischen Präparaten hingegen waren doch da und dort im Marke und in der bindegewebigen Hülle der rechten Nebenniere kleine Geschwulstmetastasen nachweisbar. Im Uebrigen war Alles normal, nur war das gesammte Gewebe sehr hyperämisch und die kleinen Arterien zeigten die 
Erscheinungen der fibrösen Endarteritis, einige zugleich hyaline Degeneration der intimalen und medialen Haut. Entzündungsherde in der Umgebung kleinerer Gefässe fehlten rechterseits, links waren sie sehr zahlreich sowohl in der Nähe von Gefässen, als von Nervenstämmchen vorhanden. Auch Geschwulstmetastasen waren in der Wandung grösserer Gefässe nachweisbar, an einer grösseren Vene sogar in der Intima.

\section{Die Semilunarganglien.}

Wie schon hervorgehoben, waren die Semilunarganglien, bezw. der Plexus solaris mit den zu den Nebennieren führenden Nervenzweigen in eine Geschwulstmasse eingebettet, welche eine Präparation nicht mehr zuliess. Um aber trotzdem eine mikroskopische Untersuchung dieser Theile zu ermöglichen, schnitt ich aus der grossen Geschwulstmasse an denjenigen Stellen, wo ich die Semilunarganglien zu vermuthen Anlass hatte, grosse Würfel heraus und bereitete diese zur Herstellung mikroskopischer Schnitte durch Einbetten in Celloidin vor. Auf diese Weise ist es mir denn auch gelungen, ganz gentigend ubersichtliche Präparate von den Semilunarganglien und einigen Nervenstämmen zu erhalten.

In der nächsten Umgebung der Semilunarganglien, zwischen diesen und der eigentlichen Geschwulstmasse, befand sich atrophisches Fettgewebe und faseriges Bindegewebe, reich durchsetat von mehr diffusen oder mehr circumscripten Herden von Rundzellen, welche bisweilen innigere Beziehungen zu Gefässen erkennen lassen.

Auf den ersten Blick imponiren diese Rundzellenherde als Granulationsgewebe; indessen zeigen aber doch die Zellen und namentlich deren Kerne sowohl nach Grösse, als nach Intensität der Färbung ein Verhalten, welches den Zellen der sarkomatösen Neubildung eigenthümlich war. Ich habe mich daher der Annahme nicht verschliessen. können, dass es sich bei vielen dieser Herde um beginnende Geschwulstbildung handelt.

Die bindegewebige Hülle der Semilunarganglien ist verdickt, ausserdem da und dort durchsetzt von den bereits erwähnten kleinen Herden, bisweilen auch von deutlich ausgesprochenen Sarkommetastasen.

Im Innern der Semilunarganglien ist eine Bindegewebevermehrung ganz evident; sie erreicht fast durchweg beträchtlichere Grade als beim ersten Falle. Es ist eine diffuse Bindegewebewucherung zu unterscheiden von dem herdweisen Auftreten von Rundzellenanhäufungen in der Umgebung der Gefässe und vieler Ganglienzellengruppen. Viele von diesen Rundzellenanhänfungen müssen entschieden als circumscripte Entzündungsherde aufgefasst werden. Indessen sind auch viele von ihnen wieder besonders gekennzeichnet durch grössere und stärker tingirte Kerne, so dass man auch hier wieder an Vorstadien sarkomatöser Neubildungen denken muss, zu welchen die Keime durch embolische Processe an die betreffenden Stellen gefuhrt worden sind. An mehreren Stellen waren unzweifelhaft als Sarkommetastasen anzusprechende Herde von der bindegewebigen Hülle der Ganglien nach dem Innern zu gewuchert. Auch im Innern waren ähnliche Geschwulstherde, ohne jeden nachweisbaren Zusammenhang mit Gefässen oder mit der Kapsel. Sehr oft waren solche Metastasen umgeben mit einem Hofe kleinerer, aber intensiv gefärbter Rundzellen. 
Veränder. des sympatb. u. cerebrospinal. Nervensyst. b. Addison'scher Krankh. 301

Die Ganglienzellen sind mehr als gewöhnlich pigmentirt; wohl keine einzige ist frei von Pigmentablagerung geblieben. Sie sind kleiner als im Falle I, und oft sind deren Formen und Structur namentlich da, wo die Rundzelleninfiltration höhere Grade angenommen hat, schwer zu erkennen, da oft nur ein Pigmenthäufchen die Lage einer Ganglienzelle andeutet. Auch scheinen die Ganglienzellen der Zahl nach geringer zu sein, als bei Fall I, doch beruht dies allerdings nur auf einer Schätzung beim Vergleich von Schnitten, welche möglicher Weise ganz verschiedenen Stellen der Ganglien entsprechen, und es ist infolgedessen der Werth dieser Vermuthung nur gering anzuschlagen.

Die Kerne der Ganglienzellen haben den Farbstoff schwer, sehr oft gar nicht angenommen.

Die Nervenfasern und Bündel in den Ganglien sowohl, als in den ansserhalb der Ganglien verlaufenden und auf den topographischen Schnitten getroffenen Nerven zeigen im Allgemeinen ganz analoge Veränderungen, wie sie bei Fall I beschrieben worden sind. Nur ist erwähnenswerth, dass an den im Ganglion verlaufenden Nerven eine Kernwucherung viel deutlicher zu Tage tritt.

Fast kein einziges der in der Umgebung der Ganglien verlaufenden Nervenstämmchen und Stämme bietet mehr normale Verhältnisse dar. Entandliche Infiltrationen des Perineurium und des die Nerven durchsetzenden Bindegewebes finden sich in allen Stadien und Intensitätsgraden; bisweilen ist auch der Ausgang dieser Infiltrationen von Gefässen deutlich nachweisbar. Desgleichen finden sich da und dort an Nervenquerschnitten sarkomatöse Infiltrationen, vorwiegend im Perineurium.

Die hochgradigsten Veränderungen dieser Art zeigen mehrere grössere Nervenstämme, welche vermuthlich den Splanchnicis zngehören. Das Perineurium zeigt sich hier mächtig gewuchert, sehr reich an runden und spindelförmigen Zellen. Die Gefässe im Perineurium und im Innern der Nervenstämme haben stark verdickte und infiltrirte Wandungen, grösstentheils mit verengertem Lumen; auch Thrombenbildungen sind hin und wieder nachweisbar. Erweiterte und mit Thrombusmasse ausgefullte Lymphgefässe habe ich ebenfalls nachweisen können.

Von derartig veränderten Gefässen gehen mächtige Bindegewebewucherungen aus, welche den Nerv durchsetzen und viel von den Nervenfasern zerstörten. Von den letzteren ist an vielen Querschnitten durch grössere und kleinere Nerven nur wenig mehr ubrig geblieben, gleichgültig, mit welchen Färbungsmethoden der Nachweis von deren Ueberresten versucht worden ist. Oft gab die Weigert'sche Methode ganz negative Resultate in dieser Hinsicht, und nur die Carminpräparate ermöglichten es noch, die hochgradigst alterirten Nervenquerschnitte als solche anzusprechen.

Die Veränderungen der Gefässe, namentlich der kleinen Arterien, weisen in nächster Näbe der erkrankten Nebenniere und Semilunarganglien die höchsten Grade auf. Fast ansnahmslos bieten sie das Bild der fibrösen Endarteritis dar, welcher die hyaline Degeneration der Intima und Media nachfolgte. Ausser einer entzündlichen Infiltration der adventitiellen Lymphräume sind nicht selten sarkomatöse Elemente und 
Herde daselbst zu sehen gewesen. Sarkommetastasen unter dem Endothel einer grossen Vene habe ich bereits früher erwähnt. In Form einer polypösen Wucherung ragte die noch von Endothel überzogene Geschwulstmasse in das Lumen hinein.

Obgleich die rechte Nebenniere normal war, waren im Grossen und Ganzen die Semilunarganglien beider Seiten sowohl quantitativ als qualitativ gleichmässig entartet. Es kann dies nicht besonders auffällig sein, da auf beiden Seiten die Semilunarganglien, oder, mit anderen Worten, da der ganze Solarplexus von derselben Geschwulstmasse umgeben war und mithin unter derselben Ursache zu leiden hatte.

\section{Die Grenzstränge des Sympathicus.}

Wenn man die beiderseitigen Grenzstränge des Sympathicus mit ihren Ganglien von den Stellen ab, wo sie sich in der beschriebenen Geschwulstmasse verlieren, stufenweise nach oben verfolgt, so zeigt sich bei dem Vergleichen der Präparate von beiden Seiten schon auf den ersten Blick, dass es sich auf beiden Seiten um die gleichen Veränderungen handelt.

Die Verdickung der Grenzstränge, welche oberhalb des Tumors auffiel, war auf beiden Seiten dadurch bedingt, dass das die Ganglien und den Grenzstrang umgebende Gewebe einestheils durch Bindegewebsvermehrung, anderentheils durch entzündliche und sarkomatöse Infiltration, wozu noch beträchtliche Hyperämie und seröse Durchtränkung hinzukamen, an Masse zugenommen hatte. Es reichte dieser Process annähernd bis zur Abgangsstelle des Splanchnic. major herauf und nahm dann beiderseits ganz allmählich nach oben hin an Intensität und Ausdehnung ab.

Wirkliche Geschwulstmassen waren nicht, wie es bei der Besichtigung mit freiem Ange da und dort den Anschein hatte, im Grenzstrang selbst oder in dessen Ganglien eingelagert, sondern immer waren solche Herde nur in den Scheiden oder noch entfernter im umgebenden Bindegewebe oder atrophischen Fettgewebe eingelagert.

Was das Bindegewebe in den Grenzsträngen und dessen Ganglien betrifft, so war es in unregelmässiger Weise da und dort entschieden vermehrt. Sehr oft liessen sich auch - oft schon mit freiem Auge - an den Schnitten kleine Herde von Rundzellen nachweisen, welche entweder mit den Gefässen oder mit der bindegewebigen Hülle in näherer Beziehung standen. Die Gefässe, der Nerven und Ganglien sowohl, wie diejenigen des umgebenden Gewebes waren durchweg prall mit Blut angefullt. An den kleinen Arterien war das Bild der fibrösen Endarteritis fast ausnahmslos, sehr oft in höheren Intensitätsgraden zu erkennen. Hyaline Degeneration war bisweilen, aber nicht immer nachgefolgt.

Die Ganglienzellen zeigten die Processe der Schrumpfung und Pigmentirung in den unteren Stufen, d. h. in der Nähe der Semilunarganglien, in ganz beträchtlichem Grade. Je weiter oben aber die Stufenschnitte angelegt waren, um so weniger intensiv war die Pigmentirung und die Atrophie der Ganglienzellen. Es war also eine ganz deutliche Abnahme der Pigmentatrophie der Ganglienzellen nach oben zu constatiren. Auch trat dieser Process nicht mehr so gleichmässig und glejchförmig an einem 
Veränder. des sympath. u. cerebrospinal. Nervensyst. b. Addison'scher Krankh. 303

Ganglienschnitt auf, sondern beschränkte sich mehr auf einzelne Gruppen von Ganglienzellen, während andere Gruppen wieder mehr geschont geblieben waren. Dass das Mehr oder Weniger dieses Processes wiederum der subjectiven Anschanung und Abschätzung unterworfen ist, brauche ich natürlich kaum hervorzuheben, doch habe ich mich dabei, so oft es anging, vergleichend an den ersten Fall und an Controlpräparate gehalten.

Von den in den Grenzsträngen, bezw. deren Ganglien verlaufenden Nervenfasern haben auch in diesem Falle wieder vorwiegend die markhaltigen Fasern gelitten. Rechterseits, wo auch die Nebenniere normal geblieben war, sind vielleicht mehr Fasern intact geblieben, als links. Auf dieser Seite aber war von den markhaltigen Fasern der breiten Kategorie auf den zahlreichen von mir untersuchten Schnitten kaum eine auf eine grössere Strecke erhalten. Wo sie nicht gänzlich fehlten, zeigten sie ausnahmslos Zerfallserscheinungen, sowohl am Marke, als an den Axencylindern. Zum Prüfen dieser Verhältnisse habe ich, wie im ersten Falle, immer einen Theil der Schnitte nach der Weigert'schen Methode, den anderen Theil mit Boraxcarmin gefärbt. Die Goldmethode habe ich sehr bald wieder aufgegeben, weil ich auf die andere Weise genügende Resultate erhielt.

Der Zerfall der Markscheiden der breiten Fasern war viel hochgradiger, als im ersten Falle. Am linken Brustsympathicus z. B. erschienen die Präparate an denjenigen Stellen, wo die markhaltigen Fasern za verlaufen pflegen, wie dicht durchsetzt mit schwarzen ungleichen Körnern, den Ueberresten des Markmantels.

Die schmalen markhaltigen Fasern scheinen resistenter gewesen zu sein. Obwohl auch an den meisten von diesen Zerklüftung und körniger Zerfall des Markes nachweisbar war, so boten doch sehr viele von ihnen entweder die rosenkranzförmige Zeichnung durch regelmässigen Abstand gequollener und atrophischer Stellen, oder etwas unregelmässiger zahlreiche spindelförmige Auftreibungen mit ganz dünnen, aber regelmässigen Contouren. - An den Carminpräparaten waren Auftreibungen, varicöse Schwellungen, Zerfall oder gänzlicher Schwund der Axencylinder nachweisbar, besonders das Letztere an den Stellen, welche den breiten markhaltigen Fasern entsprechen. Kernwucherungen waren an Längs- und Querschnitten fast überall nachweisbar.

Auf der rechten Seite waren diese Processe des Zerfalls markhaltiger Fasern noch im obersten Halsganglion in derselben Intensität wie tiefer unten nachweisbar. Linkerseits, wo von vornherein die Intensität des Zerfalls eine grössere war, zeigte das obere Halsganglion, gleichwie der unterhalb desselben gelegene Theil des Grenzstrangs schon makroskopisch abweichende Verhältnisse, welche einer besonderen Erwähnung bedürfen.

Das linke obere Cervicalganglion. Fig. $8 \mathrm{~b}$.

Von dem untersten linken Halsganglion aufwärts nimmt der Grenzstrang an Dicke ab. Ein mittleres, bezw. zweites Halsganglion fehlt linkerseits, während es rechterseits vorhanden ist. In der Nähe des geschwulstähnlich degenerirten oberen Halsganglion beträgt der Querschnitt durch den Sympathicus nur etwa noch ein Drittel des Brustsympathicus derselben Seite. 
Bei der mikroskopischen Untersuchung erkennt man, dass der Nerv nur von einem schmalen Bande von Nervenfasern gebildet wird. Von breiten markhaltigen Fasern sind nur noch Ueberreste des Markmantels vorhanden. Die schmalen markhaltigen Fasern sind noch in ziemlicher Menge vorhanden, zeigen aber die schon mehrfach erwähnten Degenerationserscheinungen. Der Raum des Querschnitts, welcher von grauen Fasern eingenommen wird, ist ebenfalls nur gering und ist, soweit sich dies aus Längs- und Querschnitten abschätzen lässt, nicht grösser als der von den schmalen markhaltigen Fasern beanspruchte. Ganglienzellen fehlen auf den von mir untersuchten Strecken vollständig.

Fig. $8 \mathrm{~b}$.

Fig. 8 a.

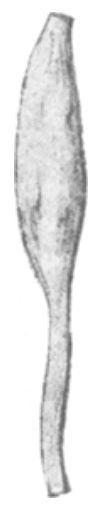

Reohtes oberstes Cervicalganglion.

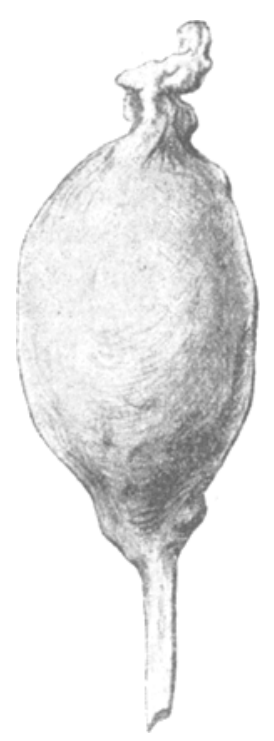

Linkes oberstes Cervicalganglion.

Verfolgt man den Halssympathicus weiter nach oben, so beginnt derselbe $1^{1 / 2} \mathrm{Cm}$. unterhalb des Ganglion cervic. suprem. allmählich an Dicke wieder zuzunebmen, um dann direet in den diesem Ganglion entsprechenden Tumor überzugehen.

Bei der Anlegung eines Schnittes durch das obere Halsganglion in der Längsaxe des Halssympathicus stelit sich die Schnittfläche so dar, dass aus derselben dentlich ersichtlich ist, wie sich der Tumor zum Ganglion und zum Nerven verhält. Der ganze Tumor ist überzogen mit einer dicken, fibrösen Kapsel, welche sich nach oben und unten direct auf die Nerven fortsetzt, also identisch ist mit deren fibröser Scheide.

Der untere Pol der Geschwulst gehört noch ausschliesslich dem Ganglion an; dann wird aber das Gewebe des letzteren durch die Geschwulstmasse derart auseinandergedrängt, dass die letztere von dem Ge- 
Veränder. des sympath. u. cerebrospinal. Nervensyst. b. Addison'scher Krankh. 305

webe des Ganglion wie von einer dünnen Hülle umgeben wird. Dementsprechend zeigen die Schnitte unter dem Mikroskope unter der äusseren bindegewebigen Umhüllung eine dünne Lage von nervösen Elementen, als Ganglien und Nervenfasern, welche in mehr oder weniger hochgradiger Weise degenerirt und verändert erscheinen. Nach innen zu grenzt sich die von Ueberresten des Ganglion gebildete Rindenschicht nicht scharf vom Tumor ab, sondern sie geht allmählich und ohne deutliche Grenze in den letzteren über.

Was den Charakter der Neubildung im Ganglion betrifft, so erscheint deren Gewebe schon bei der Durchschneidung ziemlich derb. Auf der Schnittfläche treten breitere und schmälere Züge von Bindegewebe deutlicher hervor, ebenso grössere und kleinere Gefässlumina mit hämorrhagischen, bezw. pigmentirten Herden in ihrer Umgebung.

Unter dem Mikroskope bieten sich an verschiedenen Stellen ganz verschiedene Bilder dar. Hier präsentirt sich eine Stelle des Tumors so, als ob der Schnitt durch ein Netzwerk reich verzweigter fibröser Bündel geführt worden wäre. Wo solche Bündel quer getroffen sind, treten Häufchen von runden and ovalen Zellen zu Tage mit grossen, intensiv gefärbten Kernen. Wo die Bündel längs getroffen sind, sind runde Zellen ebenfalls in reichlicher Zahl vorhanden, ausserdem aber viele schmale und lange spindelförmige Zellen, ähnlich denjenigen des Neurileum von Nervenfasern. Die Grundsubstanz an diesen Stellen ist eine mehr fibröse, so dass man aus diesen Bildern den Eindruck gewinnt, als handle es sich um ein sehr zellreiches $\mathrm{Neu}$ rofibrom.

An anderen Stellen, und zwar uberwiegend, ist der Charakter der Neubildung mehr cellulär. Da werden die grossen Rundzellen prävalent, ihr Kern ist sebr gross und intensiv gefärbt, und die Zellen haben entschieden grösste Aehnlichkeit mit den Zellen der Neubildung in der linken Nebenniere, im Solarplexus, im Magen, in den Lymphdrüsen und den übrigen Organen. Dabei fehlen Entzündungserscheinungen innerhalb des Tumors keineswegs. Die Umgebung der Gefässe ist infiltrirt und zwar mit Rundzellen, welche kleiner sind als diejenigen, welche ich als sarkomatös angesprochen habe. Kleine Blutungen finden sich in der Nachbarschaft solcher Gefässe, ausserdem Anhänfungen von Pigment in der Umgebung mehrerer Gefässe, zum Theil frei in den Saftspalten des Bindegewebes, zum Theil in runde und spindelförmige Zellen eingeschlossen.

Nach der Peripherie zu ist, wie schon erwähnt, dicht unter der bindegewebigen Hülle ein Mantel vom Gewebe des Ganglion erhalten geblieben. Da finden sich noch vereinzelte oder in Gruppen zusammenstehende, meist hochgradig pigmentirte und stark geschrumpfte Ganglienzellen, sehr oft ohne färbbaren Kern. Das Bindegewebe ist beträchtlich vermehrt, ausserordentlich zellreich. Von markhaltigen Fasern sind in der ganzen Peripherie des Tumors, auch im unteren Pol desselben, wo der Charakter des Ganglion noch am deutlichsten gewahrt blieb, nur noch ganz vereinzelte, in Degeneration begriffene kurze Strecken von Fasern ubrig geblieben.

Die einheitliche Deutung des vielgestaltigen histologischen Bildes bietet nicht geringe Schwierigkeiten. Da man jedoch nicht wohl annehmen kann, dass es sich in diesem Ganglion supremum um eine selbständige Neubildung handelt, welche als Fibro-Neuro-Sarkom bezeichnet werden müsste, 
halte ich mich zu der Deutung berechtigt: es handelt sich um eine Sarkommetastase im Innern des obersten Halsganglion.

\section{Die Nervi splanehnici}

boten beim Vergleiche der beiderseitigen Stämme schon makroskopisch deutliche Verschiedenheiten. Oberhalb des Tumors hatte der linke Splanchnicus major in der Ausdehnung einiger Centimeter das Aussehen eines dünnen Fadens, war aber dabei derber anzufühlen. Höher oben wurde er wieder dicker und war sogar bis herauf zur Abgangsstelle vom Brustgrenzstrang entschieden dicker als normale Vergleichspräparate. Auch der Splanchnicus minor war auf der linken Seite zu einem dünnen Faden atrophirt.

Der rechte Splanchnicus major war, soweit er vom Brustgrenzstrang bis zur Einsenkung in die über der Wirbelsäule gelegene Neubildung reichte, gleichmässig verdiekt. Der Splanchnicus minor dieser Seite war ebenfalls voluminöser, als auf der linken Seite.

Mikroskopisch stellten die linksseitigen Nervi splanchnici majores and minores in den atrophischen Partien nur bindegewebige Stränge dar. Markhaltige Fasern waren mit der Weigert'schen Hämatoxylinfärbungsmethode nicht mehr nachzuweisen.

An höher oben entnommenen Stufenschnitten war das Perineurium externum und internum mächtig verdickt, gewuchert und zellig infiltrirt. Die Gefässe waren verdickt und vielfach von Infiltrationsherden umgeben. Die markhaltigen Fasern boten in ausgesprochenster Weise die Erscheinungen der parenchymatösen Degeneration dar. Auch auf der rechten Seite waren im Splanchnicus major und minor neben hochgradigem Zerfall markhaltiger Fasern Kernwucherung, interstitielle Bindegewebsvermehrung und mächtige Verdickung des Perineurium mit Gefässalterationen vorhanden.

Die Intervertebralganglien.

Bei der Präparation dieser Ganglien liessen die linksseitigen unteren Brust- und oberen Lendenintervertebralganglien eine Vergrösserung gegen die rechtsseitigen erkennen; auch erschienen sie gleichzeitig stärker pigmentirt. Indessen stellte sich bei genauerer Untersuchung und namentlich beim Vergleiche mit den beiderseitigen oberen Cervicalintervertebralganglien und beim Vergieiche mit den Dorsalintervertebralganglien heraus, dass wohl die cervicalen und lumbalen Spinalganglien grösser waren, als die dorsalen, dass aber unter den beiderseitigen Ganglien aus gleicher Höhe wirkliche Grössenunterschiede, welche auf die Ganglien selbst zu beziehen gewesen wären, nicht vorlagen. Die scheinbare Vergrösserung der linken dorso-lumbalen Ganglien war bedingt durch sarkomatöse Infiltration des Bindegewebes und Fettgewebes, in welches diese Ganglien eingebettet waren.

Principielle histologische Unterschiede im Verhalten der Ganglien und der zugehörigen Nerven habe ich bei den aus verschiedener Höhe der Hals-, Brust- und Lendenwirbelsäule entnommenen Ganglien nicht constatiren können, auch $z$ wischen links und rechts war, geringe graduelle $\mathrm{Ab}$ stufungen abgerechnet, kein prägnanter Unterschied, so dass es wohl gerechtfertigt ist, den Befund zusammengefasst wiederzugeben. 
Veränder. des sympath. u. cerebrospinal. Nervensyst. b. Addison'scher Krankh. 307

Die bindegewebige Hülle der Ganglien ist wiederum beträchtlich verdickt, ihre äussere Schicht zellärmer und mehr fibrös beschaffen, ihre innere Schicht sehr zellreich und ausserordentlich stark pigmentirt. Von ihr gehen breite, zellreiche und ebenfalls stark pigmentirte Züge nach innen, das Ganglion nach verschiedenen Richtungen durchsetzend; ähnliche Züge folgen den Gefässen. Von den Ganglienzellen tragen die Mehrzahl die Merkmale der Pigmentatrophie. Nur wenige Zellen sind pigmentfrei und füllen dann den ihnen zugehörigen Kapselraum noch einigermaassen aus; die meisten Zellen sind geschrumpft, und es lässt sich fast überall nachweisen, dass mit zunehmender Verkleinerung der Zellen eine grössere Pigmentirung derselben stattgefunden hat. An den nach Weigert'scher Methode behandelten Schnitten erscheinen viele der Zellen wie kleine und grössere schwarze Pigmentklumpen.

Die durch Schrumpfungsprocesse an den Ganglienzellen freigewordenen Räume der Kapsel sind vielfach leer; vielfach sind sie auch ausgefüllt mit mehr oder weniger trübem, körnigem Inhalt, auch Fibrinfäden und Zellen und hyalinen Tropfen.

In der Umgebung der Kapseln ist an den meisten Präparaten eine mehr fleckweise, entztindliche Infiltration mit Rundzellen, wodurch einerseits die Kapselmembranen verdickt und mehrschichtig erscheinen, und wodurch andererseits ganze Gruppen von Ganglienzellen an den mit Hämatoxylin oder Alauncarmin oder Boraxcarmin gefärbten Präparaten in einen Herd von Rundzellen eingelagert erscheinen.

Das Verhalten der Nervenfasern innerhalb der Ganglien ist ein ziemlich wechselndes. In vielen Ganglien haben die in demselben verlaufenden Fasern verhältnissmässig wenig gelitten, trotzdem, dass die vom Sympathicus zum Ganglion tretenden Bündel, viele Fasern im Intercostalnerv und die hinteren Wurzeln unverhältnissmässig stark degenerirt sind. An anderen Ganglien zeigen allerdings auch die in demselben verlaufenden Fasern denselben Grad von Degeneration, wie die mit dem Ganglion in Verbindung tretenden Nerven. In keinem Ganglion fehlt jedoch eine Degeneration von Nervenfasern.

Durch die Untersuchung einer ausserordentlich grossen Zahl von Schnitten von verschiedenen Ganglien habe ich das Urtheil gewonnen, dass die das Ganglion mit dem Sympathicus verbindenden Fasern am meisten degenerirt sind; ebenfalls hochgradige Degenerationsprocesse lassensichanden vom Ganglionzum Rückenmark gehenden hinteren Wurzelfasern nachweisen. Am wenigsten, aber immerbin noch beträchtlich, haben die Fasern des Intercostalnervs gelitten. Abgesehen von der Degeneration und dem Schwund der Fasern sind im letztgenannten Nerven ausserordentlich viele schmale markhaltige Fasern enthalten.

Im Gegensatze zu diesen vorwiegend sensibleu Nervenbahnen zeigen Querschnittspräparate, an welchen neben den Spinalganglien die vor deren motorischen Wurzeln getroffen wurden, dass die letzteren (eine geringgradige und kaum als pathologisch anzusprechende Verdickung des Perineurium ansgenommen) voll kommen normal erscheinen. Es muss infolgedessen angenommen werden, dass die degenerirten Fasern des 
gemischten Intercostalnervs nicht motorische, sondern nur sensible, bezw. trophische gewesen sein können.

Die Gefässe in den Spinalganglien zeigen durchweg dasselbe Verhalten: Hyperämie, Veränderungen der Gefässwand, namentlich der Intima, und Infiltration der perivasculären Räume mit Rundzellen, frische und ältere Hämorrhagien.

Man ist aus diesem Befunde berechtigt, die Veränderungen am Ganglion aufzufassen als einen chronischen Entzindungsprocess, der einerseits von den Gefässen ausgeht und zu Verdickung der Kapsel und Vermehrung des interstitiellen Bindegewebes, Blutungen, Pigmentbildung im Bindegewebe und Pigmentatrophie vieler Ganglienzellen führt. Andererseits zeigen die vom Ganglion zum peripheren Nerven, zum Sympathicus und zum Rückenmark gehenden Fasern hochgradige Degenerationserscheinungen, welche zum Theil durch die Veränderungen am Sympathicus bedingt, zum Theil aber auch von den Degenerationsprocessen an den Ganglienzellen der Spinalganglien abhängig sein mögen.

\section{Gehirn und Rückenmark.}

Das Schädeldach ist dick und compact und misst an seiner grössten Dicke, dem Stirnbein entsprechend, $8 \mathrm{Mm}$., an der dünnsten Stelle des Scheitelbeins nur $4 \mathrm{Mm}$. Die Nähte sind deutlich zu erkennen, die Diploe wenig entwickelt.

Die Dura mater haftet an der Pia an mehreren Stellen fester an, ist glatt und glänzend und zeigt zahlreiche Pachioni'sche Granulationen. Im Sinus longitudinalis wenig hellrothes Gerinnsel. Das Gehirn ist gross, die Pia glatt und glänzend, ihre Gefässe an der Convexität ziemlich stark mit Blut gefullt. Die Substanz der Grosshirnhemisphären erscheint sehr blass, mit einem Stich ins Grünliche, blutarm und nur mässig feucht. Die Seitenventrikel sind von normaler Grösse und enthalten nur wenig klares, etwas gelbliches Serum. Auf Frontalschnitten ist im Grosshirn, in Pons und Kleinhirn nichts Abnormes zu erkennen.

Die Dura mater spinalis ist unverändert; die Pia mater klar, feucht und glänzend, die Venen der Rückseite entsprechend stärker mit Blut gefullt und weiter.

Auf Querschnitten zeigt die Substanz des Ruckenmarks eine weiche Consistenz, quillt auf der Schnitffäche hervor, mässig feucht. Graue und weisse Substanz sind deutlich von einander geschieden, bieten aber keine besonderen Veränderungen.

Nach der Härtung in Müller'scher Flüssigkeit traten aber an frisch angelegten Querschnitten des Rutckenmarks ganz eigenartige Verfärbungen auf, welche ich in den Zeichnungen der Fig. 9a-e wiederzugeben versuche. Ganz ähnlich, wie im Falle I, verhält sich die graue Substanz in der ganzen Länge des Rückenmarks vollkommen normal und hat die bekannte graugrünliche Verfärbung angenommen. Ebenso verhalten sich Vorder- und Seitenstränge durch das ganze Rückenmark bindurch, wie dies normale Präparate zu thun pflegen. Nur an den Hintersträngen haben bestimmte Felder des Querschnitts nicht die normale dunkelgrüne Färbung angenommen, sondern sind grauweiss geblieben und bieten etwa dasselbe Colorit, wie die graue Substanz. 
Veränder. des sympath. u. cerebrospinal. Nervensyst. b. Addison'scher Krankh. 309

Entsprechend dem oberen Halsmark geht zu beiden Seiten der hinteren Längsfurche an der Grenze zwischen Goll'schem und Burdach'schem Strange eine etwa $1-1^{1 / 2} \mathrm{Mm}$. breite graue Zone nach innen und schneidet sich in der Medianlinie, so dass die grau gebliebene Figur etwa die Gestalt eines gleichsehenkeligen Dreiecks mit schwach nach aussen convexen Seiten annimmt. Eine ganz schmale, grau gebliebene Randzone verläuft an der Peripherie der Hinterstränge von der Austrittsstelle der hinteren Wurzeln der einen Seite zu der entsprechenden Stelle der anderen Seite. (Fig. 9a.) In der Halsanschwellung verbreitert sich allmählich der graue Streif zwischen Goll'schen und Burdach'schen Strängen und erscheint wie ein Keil $\mathrm{z}$ wischen diesen beiden Regionen. (Fig. 9b.) Zugleich rückt an immer tieferen Stufen die grau gebliebene Zone immer mehr an die Hinterhörner heran, indem sie sich auch noeh gleichzeitig verbreitert. Zwischen mittlerem und unterem Dorsalmark (Fig. 9c d) haben die grauen Felder ihre grössten Ausdehnungen angenommen, liegen den Hintersäulen dicht an und lassen die Goll'schen Stränge nahezu ganz unberithrt. Noch weiter abwärts nehmen diese Felder an Breitenausdehnung wieder $a b$, und von der Lendenanschwellung bleibt dann nur noch ein schmaler grauer Sporn an der Stelle der hinteren Medianfurche, welcher nur wenig nach der Tiefe reicht. (Fig. 9e.)

Beim Vergleichen dieses immerhin auffälligen Befundes mit Rückenmarksquerschnitten anderer, z. B. normaler Fälle lässt sich nicht bestreiten, dass unter dem Einflusse der Härtung häufig genug verschiedene Färbungen in der weissen Substanz vorkommen. Es handelt sich da meistens $\mathrm{um}$ blassere, graugriłne Färbungen der Randpartien. Niemals aber findet man so bestimmte Zeichnungen, wie im vorliegenden Falle, welche ihrerseits wiederum die allergrösste Aehnlichkeit mit dem Befunde am Rückenmark des Falles I d I e r $\left(I_{\text {. }}\right)$ darbieten. Ich bestreite ja nicht, dass, soweit die blasse, periphere Zone der Hinterstränge in Betracht kommt, eine gewisse Zufälligkeit bei der Härtung mitgespielt haben mag. Bei den bestimmten Zeichnungen der grauen Felder im Innern des Rückenmarks ist man aber doch versucht zu glauben, dass es sich um pathologische Zustände handelt, welche sich an den beschriebenen Stellen entweder vorbereiten, oder mehr oder weniger abgespielt haben.

Untersucht man nun ohne jede Voreingenommenheit die gefärbten, mikroskopischen Präparate, so lässt sich nicht verkennen, dass diese schon bei der Betrachtung mit freiem Ange gewisse Abweichungen von der Norm darbieten.

Namentlich an den Boraxcarminpräparaten ist die in Fig. 9 gegebene Zeichnung ganz deutlich wiederzuerkennen; ebenso an Weigert-Präparaten, wemn da auch etwas weniger deutlich. Die Schnitte aus dem Dorsalmark lassen ebenfalls in den Hintersträngen dunkler und heller gefärbte Felder in einer gewissen Regelmässigkeit erkennen, welche allerdings nicht ganz congruent sind mit den Bildern an ungefürbten Rückenmarkssegmenten. An den (mit Boraxcarmin) gefärbten Schnitten stellen sich die dunkler gefärbten Felder so dar, dass sie vom Halsmark abwärts bis zum unteren Dorsalmark an den Schnitten die Gestalt eines Keiles oder Dreiecks haben, dessen Spitze im unteren Cervical- und oberen Dorsalmark dicht hinter der grauen Commissur gelegen ist, weiter unten jedoch 
immer mehr nach hinten rückt, in der Weise, dass sie z. B. am Lendenmark des Keiles nur noch etwa zur Mitte der hinteren Längsfissur heranreicht. Im oberen Dorsalmark hat der Keil seine grösste Breite und reicht sogar bis über die Goll'schen Stränge hinaus. In der Mitte des Dorsalmarks beginnt eine Verschmälerung einzutreten, welche nach abwärts immer mehr zunimmt, so dass im Lendenmark nur noch die der hinteren Längsfissur zunächst anliegenden Partien dunkler gefärbt erscheinen. Auch an den gefärbten (Carmin-)Präparaten erscheinen die zwischen dem dunkleren Keile und den Hintersäulen gelegenen Theile, namentlich die den letzteren dicht anliegenden Partien auffallend hell.

Unter dem Mikroskope erscheinen die erwähnten, an Boraxcarminpräparaten dunkler roth, an Weigert-Präparaten heller und mehr brännlich aussehenden Gebiete etwas anders, als an den übrigen Stellen der weissen Substanz, oder als an den entsprechenden Stellen normaler Vergleichspräparate. Die Neuroglia ist an den betreffenden Stellen entschieden verbreitert, sie erscheint wie gequollen und weist da und dort Kernvermehrung auf. Die Lücken für die Nervenfasern sind dementsprechend kleiner, die Fasern selbst sind nicht mehr so regelmässig angeordnet, entweder sehr schmal, oder etwas aufgequollen, sehr oft excentrisch gelagert. Ganz prägnante Zerfallserscheinungen an Markhüllen oder Axencylindern fehlen aber. Im Gegensatz hierzu stellen sich die helleren, den Hintersäulen anliegenden Partien so dar, als ob hier das Reticulum für die Fasern grössere Maschen darböte, als ob das Gewebe rareficirt wäre.

Im ganzen übrigen Rückenmarke ist nichts Abnormes mehr nachweisbar, insbesondere habe ich an der grauen Substanz des Ritckenmarks, weder an den Ganglienzellen, noch an den Fasern etwas Besonderes anffinden können. Ein Centralcanal ist allerdings im eigentlichen Sinne des Wortes nicht vorhanden, d. h. ein solcher mithumen versehener Canal ist nur im obersten Halsmark deutlich. Von da $a b$ ist an Stelle des Canals ein ziemlich unregelmässig beschaffener Strang vorhanden, welcher sich bis herab in den Conus terminalis auf Querschnitten als eine aus einer grösseren Zahl von mehr oder weniger zellreichen Ependymzellengruppen präsentirt. Entzündungserscheinungen in der Nähe dieser Ependymzellengruppen fehlen.

Auch die Medulla oblongata habe ich einer mikroskopischen Untersuchung unterzogen, indem ich sie theils in Stufenschnitte, theils in Serienschnitte (Vaguskern) zerlegte. Ich habe nur negative Resultate erhalten und an Ganglienzellen und Nervenfasern nur ganz normale Befunde constatirt, deren Detailbeschreibung unnöthig erscheint. Eine kleine frische Ekchymose unter dem ependymalen Uebergang des 4 . Ventrikels habe ich für bedeutungslos gehalten.

Vom Gross- und Kleinhirn kamen Würfel aus den Stirn-, den Schläfenund den Hinterhauptslappen, auch ans den Basalganglien, dem Pons und den Kleinhirnhemisphären zur Untersuchung. Bezüglich des Untersuchungsresultates kann ich mich aber kurz fassen, indem ich ansser einer geringfügigen Verdickung der Arterienintima nirgends eine Abweichung von der Norm habe constatiren können. 
Veränder. des sympath. u. cerebrospinal. Nervensyst. b. Addison'scher Krankh. 311

\section{Vagus and periphere Nerven.}

Einen Befund von mehr allgemeinem pathologischen Interesse bot der linke Nerv. vagus dar. Beim Untersuchen der Carotis, um das Verhalten der Gefässwandungen grösserer Arterien kennen zu lernen, fiel mir die ausgedehnte Degeneration des anf den betreffenden Schnitten mitgetroffenen Nerv. vagus auf. Ich verfolgte deshalb den Nerven auf grössere Strecken, und fand dabei an einer Stelle, wo der Nerv von Geschwulstmasse ganz umscheidet war, folgendes Verbalten: Im Perineuriuth traten zuerst kleinere metastatische Sarkomherde auf; diese nahmen an Ausdehnung immer mehr zu, ragten keilförmig nach dem Innern des Nervs hinein uad bewirkten dadurch eine naheza vollständige Zweitheilung des Vagus in der Längsrichtung. Diese Zweitheilung wird vollständig da, wo ein zweiter Geschwulstherd an der gegenüberliegenden Stelle ebenfalls keilförmig nach innen gewachsen ist und die Spitzen beider Keile etwa in der Mitte des Nervs zusammenstossen. Es ist wohl erklärlich, dass bei diesen Veränderungen die Fasern des Vagus Noth gelitten haben. Entzündliche Verdickung des Perineurinm, in demselben kleine Hämorrhagien, Kernwucherung im Innern, Schwund zahlreicher Fasern und Degenerationserscheinungen an vielen der bestehenden Fasern finden sich an den entsprechenden Präparaten deutlich ausgesprochen. Bemerkenswerth ist nur, dass diese Degenerationserscheinungen auch centralwärts von diesem Tumor im Nerven nachweisbar sind, wenn auch in geringerem Grade als peripher.

Leider habe ich nur den linken Vagus conservirt und bin deshalb nicht in der Lage, zu entscheiden, ob die vorliegende Vagusdegeneration eine zufällige, durch die Lage der Neubildung hervorgerufene ist, oder ob es sich um ein Verhalten des Vagus handeln könnte, welches demjenigen im I. Falle vergleichbar wäre.

Von den peripheren spinalen Nerven kamen der Nerv. medianus, cruralis, isehiadicus und ein Hautast des Nerv. cruralis zar Untersuchung.

Die drei ersteren boten bezüglich des mikroskopischen Bildes ein vollkommen übereinstimmendes Bild dar.

Das Perineurium zeigte sich beträchtlich verdickt, so dass die einzelnen Nervenbündel sehr weit von einander abstanden; durchgehends waren an demselben $\mathrm{zwei}$ Schichten zu unterscheiden: eine äussere faserige und eine innere, zellreiche Schicht, welche an gefärbten Präparaten gerade wegen des Zellreichthums dunkler erschien. Von dieser inneren Schicht ausgehend, drangen Züge von mehr oder weniger ansehnlicher Breite nach innen zwischen die einzelnen Fasern oder Fasergruppen. Zahlreiche Gefässe waren in diesen Bindegewebszilgen erkennbar, in deren Peripherie gewöhnlich auch intensivere Zellinfiltration. Viele von den kleineren Arterien zeigten eine dentlich ansgeprägte Verdickung der Intima.

Alle die genannten Nerven zeigten einen nicht unerheblichen Gehalt an schmalen markhaltigen Fasern. Diese sowohl, wie die breiten markhaltigen Fasern boten vielfach die schon mehrfach beschriebenen Anzeichen der parenchymatösen Degeneration, welche beim Vergleich mit den Präparaten des I. Falles hier entschieden intensiver und ansgebreiteter war. 
Am intensivsten und auffälligsten war die Degeneration peripherer Nervenfasern in den Präparaten des Nervus cutan. fem. med. Der Gehalt an schmalen markhaltigen Fasern war nach der Schätzung etwa gleich gross wie derjenige an breiten markhaltigen Fasern; die ersteren zeigten fast ausnahmslos Zerfallserscheinungen.

\section{Die Muskeln}

bieten auf Längs- und Querschnitten ein so hochgradig verändertes Bild dar, dass ich bedaure, nur einige Stücke aus dem $\mathrm{N}$. semitendinosus gehärtet $\mathrm{zu}$ haben.

Auf Querschnitten zeigen zunächst die einzelnen Muskelfasern ein ganz verschiedenes Kaliber; die meisten Fasern sind dünner als normal und bieten zugleich statt der mehr kreisähnlichen Scheibenform ganz verschiedene, mehr polyedrische Configuration dar. Die Kerne sind gewuchert, bisweilen sind Sarkolemmschläuche vollständig mit derartigen gewucherten Kernen angefullt, so dass das Bild von Riesenzellen vorgetäuscht wird.

Das Perimysium internum ist derart gewuchert, dass die einzelnen Muskelfasern durch Bindegewebszüge von einander getrennt sind, welche sehr oft grössere Breite darbieten, als der Querschnitt der Muskelfaser beträgt. Das Verhalten dieses interstitiellen Bindegewebes ist nicht überall dasselbe; an vielen Stellen ist es mehr faserig und zellarm, an anderen Stellen, und zwar namentlich da, wo die Muskelfasern die höchste Atrophie darbieten und zahlreiche Muskelschläuche nur mit Zellen- bezw. Kernwucherungen angefullt erscheinen, ist das interstitielle Bindegewebe ansserordentlich zellreich. Diese Zellwucherung scheint von Gefässen auszugehen, wenigstens ist der grösste Zellreichthum gewöhnlich in nächster Umgebung von Gefässen zu constatiren.

Auf Längsschnitten ist das Verhalten der Muskelfasern ganz entsprechend dem angegebenen.

Die meisten Fasern sind dünner als normal; während an den bis zur Hälfte oder bis zu einem Drittel verschmälerten Fasern die Querstreifung noch deutlich erkennbar ist, verliert sie sich bei den dünneren Fasern allmählich. In vielen Schläuchen sind nur amorphe Massen contractiler Substanz, in anderen nur hellere und gewucherte Kerne. Dazwischen uberall mehr oder weniger breite und zellreiche Züge von Bindegewebe.

Es handelt sich also um eine - wahrscheinlich chronisch entzündliche - interstitielle Bindegewebewucherung mit Atrophie der Muskelfasern. Leider habe ich es versäumt, aus verschiedenen Stellen des Körpers Muskelstücke zu entnehmen, und es ist mir folglich unmöglich, Rückschlüsse auf das Verhalten der gesammten Musculatur zu machen und die Frage zu entscheiden, ob das geschilderte Verhalten ein generelles ist und vielleicht in Beziehung steht zum allgemeinen Krankheitsbilde.

\section{Herz und Gefässe.}

In Bezug auf das Herz ist im Sectionsprotokoll angegeben, dass es vou kaum mittlerer Grösse gewesen ist und in allen seinen Abtheilungen dunkles, schmieriges und klumpig geronnenes Blut enthielt. 
Veränder. des sympath. u. cerebrospinal. Nervensyst. b. Addison'scher Krankh. 313

Ueber den histologischen Befund ist nur zu erwähnen, dass die Muskelzellen klein waren, dass sich Pigment in wechselnder Menge in denselben vorfand, dass Bindegewebszlige von grösserer oder geringerer Mächtigkeit die Musculatur vielfach durchzogen.

Es ist also auch hier ein gewisser Grad von Bindegewebswucherung und Pjgmentatrophie der Muskelzellen zu constatiren gewesen, ganz ähnlich wie im I. Falle.

An den Arterien ist fast durchgehends ein mehr oder weniger augenfälliger Grad der fibrösen Endarteritis nachweisbar gewesen, ein Befund, welchem ich in Anbetracht des Alters des Individuums eine besondere $\mathrm{Be}$ deutung nicht beilegen möchte.

Nur mit Hinsicht auf die Angaben Riehl's möchte ich hier noch betonen, dass ich nirgends Thrombenbildung und infolge davon Blutungen habe beobachten können.

Von den parenchymatösen Organen, Lungen, Leber, Milz, Nieren und Lymphdrüsen waren die zur mikroskopischen Untersuchung präparirten Stücke mehr oder weniger durchsetzt von Geschwulstmetastasen (Angiosarkom) und zeigten die entsprechenden Veränderungen ihrer histologischen Structur. Sonstige pathologische Veränderungen, welche etwa mit der Addison'schen Krankheit in ursächlichen Zusammenhang zu bringen gewesen wären, fanden sich aber nicht, und ich verzichte daher auf eine detaillirte Beschreibung der einzelnen Organe. Ich hebe nur hervor, dass ausser geringgradiger Verdickung der Arterienintima nichts Abnormes vorlag, besonders fehlte in der Blut- oder Lymphbahn der Organe freies Pigment, und es fanden sich anch sonst keine Anhaltspunkte, welche etwa für die Annahme eines circulirenden Pigmentes gesprochen hätten.

Die äussere Haut und die Pigmentflecke der Mund. schleimhant verhielten sich im Allgemeinen genau so wie beim Falle I und den zahlreichen anderen ausführlich beschriebenen Fällen. Im Verhältniss zum I. Falle bestanden zwar quantitative Unterschiede, indem der Pigmentreichthum hier grösser war, als dort. Thrombenbildung und Hämorrhagien fehlten auch hier in der Haut und in der Schleimhaut.

An den Hautstellen, welche der Gegend des Halses entstammten, wo, wie früher hervorgehoben, die Haut stärkere Furchung oder oberflächliche Abschuppung zeigte, war mikroskopisch eine stärkere Verhornung bemerkbar, doch fehlten jegliche entzündliche Erscheinungen.

Wenn man die beiden beschriebenen Fälle mit einander vergleicht, so ist bei der grossen Verschiedenheit derselben in klinischer Beziehung die vollkommene Uebereinstimmung des pathologischen Befundes am sympathischen und cerebrospinalen Nervensystem in hohem Maasse auffällig:

Im ersten Falle haben wir bei Tuberculose beider Nebennieren ein verhältnissmässig frühzeitiges Stadium der Addison'schen Krankheit; im zweiten Falle bei sarkomatöser Erkrankung der einen Nebenniere und beider Semilunarganglien das Addison'sche Krankheitsbild im höchsten Stadium der Entwicklung. 
Als übereinstimmenden Befund am Nervensystem lässt sich in beiden Fällen eine Entzündung von chronischem Charakter constatiren, welche, von den Nebennieren aufsteigend, die Semilunarganglien erreicht, $\nabla$ on da in den Splanchnicis und aufwärts in den Sympathicusgrenzsträngen sich fortpflanzt und auch auf die Spinalganglien ubertritt. Auf diesem ganzen Wege findet sich als Zeichen der Entzuindung theils eine diffuse Bindegewebswucherung, theils eine herdweise Anbäufung von Rundzellen in der Nachbarschaft von Gefässen.

Dabei tragen die meisten Ganglienzellen im Sympathicus in mehr oder weniger ausgesprochener Weise die Anzeichen der Pigment. atrophie an sich.

Von den erkrankten Nebennieren ab zeigen die zu den Semilunarganglien verlaufenden Nervenäste, ferner die Splanchnici maj. et min. und die Grenzstränge des Sympathicus eine degenerative Atrophie, d. b. eine parenchymatöse Entzündung mit Zerfall und Schwund der markhaltigen Fasern und mehr oder weniger deutlich ausgesp:ochener Bindegewebshyperplasie, welche Veränderungen sich nicht allein aufwärts bis in die obersten Halsganglien verfolgen lassen, sondern sich auch von den sympathischen Grenzsträngen und Ganglien auf diejenigen Nervenbahnen fortsetzen, welche die Communication mit den Spinalganglien bewerkstelligen.

Die intervertebralen Spinalganglien sind ohne Ausnabme durch chronisch interstitielle Entzündungsprocesse hochgradig verändert. Die bindegewebige Kapsel und die interstitiellen Bindegewebszitge der Ganglien sind verdickt, hyperplastisch, stark pigmentirt und da und dort von frischeren, zellreichen, entziindlichen, zum Theil hämorrhagischen Herden durchsetzt. Die Ganglienzellen zeigen im Bereiche dieser Entzündungsherde in hohem Grade die Erscheinungen der Pigmentatrophie. Von den Nervenfasern sind die sensiblen, d. h. die zum Sympathicus tretenden, die von den hinteren Wurzeln des Rückenmarks kommenden und zahlreiche vom Ganglion zum gemischten Intercostalnerv tretende Fasern beträchtlich degenerirt, während die das Ganglion nicht berïhrenden motorischen Fasern der vorderen Wurzeln keinerlei Degenerationserscheinungen darbieten.

Von den Spinalganglien sind, wie angegeben, in den hinteren Wurzeln degenerirte Fasern bis zum Rückenmark zu verfolgen; im Rückenmark selbst sind aber Degenerationserscheinungen mit Sicherheit nicht mehr nachweisbar, obwohl makroskopische Veränderungen in einer Alteration des Tinctionsvermögens an denjenigen Stellen der Hinterstränge zum Ausdrucke kommen, welche dem Faserverlaufe der hinteren Wurzeln entsprechen würden. 
Veränder. des sympath. u. cerebrospinal. Nervensyst. b. Addison'scher Krankh. 315

Auch an den peripheren Nerven und im Vagus sind Degenerationsvorgänge in beträchtlicher Ausdehnung nachweisbar, namentlich am Vagus und den sensiblen Hautästen. Die Befunde an den vorderen Wurzeln und an den Spinalganglien sprechen dafür, dass die degenerirten Fasern in den gemischten Nerven ebenfalls sensible vielleicht auch trophische - Fasern gewesen sind.

Ist man nun berechtigt, den Addison'schen Symptomencomplex mit diesen merkwürdigen Befunden in directen Zusammenhang zu bringen?

Auf dem diesjährigen medicinischen Congress zu Wiesbaden habe ich $^{1}$ ) die Ansicht ausgesprochen, dass die Hauptgruppen dieses Symptomencomplexes, nämlich :

1, die Störungen von Seiten der Verdauungsorgane;

2. die Erscheinungen von Seiten des Nervensystems;

3. die Pigmentirung

sich in ziemlich befriedigender Weise durch die angeführten Thatsachen würden erklären lassen.

1. Die Appetitlosigkeit und das Erbrechen, die kardialgischen Beschwerden, die inconstanten und wechselnden Darmerscheinungen, als Diarrhöe und Verstopfung, finden in den Veränderungen der sympathischen Ganglien, der Sympathicusgrenzstränge, der Splanchnici und Vagi eine vollkommene Aufklärung. Auch die Hyperämie der Bancheingeweide mit consecutiver Anämie der übrigen Theile, namentlich des Gehirns, lassen sich auf die vom Sympathicus ausgehenden vasomotorischen Störungen erklärend zurückführen.

Die Veränderungen am Herzen mögen nicht nur vom Sympathicus, sondern auch von den weitgehenden Degenerationserscheinungen der Vagi abhängig sein.

2. Die Erscheinungen von Seiten des Nervensystems, Asthenie, Arbeitsunfähigkeit, rasche Ermüdung, Schwäche, Uebelkeiten, Schwindel, Ohnmacht, erklären sich zum Theil aus dem Daniederliegen der gastrointestinalen Functionen, aus der allgemeinen Ernährungsstörung und aus der ungleichen Blutvertheilung, Hyperämie der Bauchorgane, Anämie des Gross- und Kleinhirns und der Medulla oblongata, zum Theil durch die Befunde an den peripheren, besonders den sensiblen Nerven, durch die Veränderungen der Spinalganglien und der hinteren Wurzeln, vielleicht auch durch die beginnenden Veräuderungen am Rückenmarke selbst und durch die angegebenen Veränderungen der Muskeln. Ob es sich bei der Dege-

1) Verhandiungen des Congresses für innere Medicin. 1891. S. $478 \mathrm{ff}$. 
neration der Spinalganglien und bei der Degeneration zablreicher Fasern in den sensiblen Nerven um trophische Störungen, bezw. um Degenerationen trophischer Nerven handelt, vermag ich nicht endguiltig zu entscheiden. Naheliegend wäre eine solche Annahme jedenfalls.

3. Wie die Hautpigmentirung endgültig zu erklären ist, habe ich nicht den Muth jetzt schon auszusprechen. Jedenfalls handelt: es sich nicht um eine Ablagerung von im Blute circulirendem Farbstoffe, sondern um Bildung eines Pigmentes in der Haut und in der Schleimhaut.

Nach dem heutigen Stande unserer Kenntnisse über die Functionen der intervertebralen Spinalganglien lässt sich die Annahme trophischer Störungen von Seiten der letzteren jedenfalls nicht von der Hand weisen.

Seitdem habe ich mir vielfach die Frage vorgelegt, ob dieser Befund als ein charakteristischer für Addison'sche Krankheit hingestellt werden kann, d. h. ob den beschriebenen Nervenveränderungen die Erzeugung des Symptomencomplexes in der allgemeinen Weise wird zugeschrieben werden dürfen, wie ich es 'gelegentlich meines Vortrages gethan habe.

Beim Zurtickgreifen auf den I. Fall ergiebt sich als Complication der Addison'schen Krankheit tuberculöse Caries des Ellbogengelenkes und Sepsis, welche letztere einen Tag nach der Ellbogengelenksresection zum Tode fibrte.

Die auf Sepsis hindeutenden Veränderungen an der Leiche waren so unbedeutend, dass man den raschen Eintritt des Todes auch mit auf die Existenz der Addison'schen Krankheit und der durch dieselbe hervorgerufene Herzdegeneration zurückführen darf.

Es fragt sich nun: Könnte der Sepsis auch ein Einfluss auf die Veränderungen am Nervensystem zugeschrieben werden? Wie die parenchymatösen Organe insgesammt unter dem Einfluss septischer Erkrankung eharakteristische Veränderungen zeigen, so ist a priori auch anzunehmen, dass die subtilen Elemente des centralen und peripheren Nervensystems unter diesem pathologischen Zustande zu leiden gehabt haben. Nach dem Eintritt der Sepsis, d. h. nach der Operation, hat der Patient noch einen Tag gelebt; es mulssten sich also in diesem Zeitraume die auf Sepsis zurïckzuführenden Veränderungen, die parenchymatöse Degeneration im Nervensystem entwickelt haben. Wenn es nun im Einzelfalle auch kaum möglich sein mag, das Alter parenchymatöser Degenerationen nur in annähernd präciser Weise zu taxiren, so lassen sich doch immerhin ganz acute Processe von weniger 
acuten und chronischen Processen histologisch deutlich unterscheiden. Gebe ich nun auch der Vorstellung Raum, dass die Degeneration vieler markhaltiger Fasern, ebenso wie die Hämorrhagien in den Grenzsträngen des Brustsympathicus, welche keine Umwandlung rother Blutkörperchen in Pigment erkennen lassen, einem acuten Processe, wie die Sepsis ihn darstellt, zugeschrieben werden kann, so bleiben doch in den sympathischen Fasern und Ganglien, in den peripheren Nerven und Spinalganglien noch recht viele pathologische Veränderungen übrig, denen man ein höheres Alter und einen chronischen Charakter nicht absprechen darf. Ich meine die aus Rundzellen bestehenden circumscripten Entzundungsherde in den sympathischen Ganglien, die diffuse Bindegewebshyperplasie in denselben und in den Nervenfasern, und namentlich die mit stärkerer Pigmentirung einhergehenden Bindegewebswucherungen in den Spinalganglien, anch die intensive Pigmentatrophie der Ganglienzellen. Im II. Falle sind die Complicationen zahlreicher als im I. Zwei Wochen vor dem Tode trat ein intensiver Icterus auf, daneben bestand eine schwere Kachexie durch die Ausbreitung der malignen Neubildung.

Die Untersuchungen von Oppe $\mathrm{n}$ heim und Siemerling ${ }^{1}$ ) haben uns gelehrt, dass parenchymatöse Degenerationen an peripheren Nerven mit mehr oder weniger ansgesprochenen Wucherungsprocessen am Perineurium mit Kernwucherung und Verbreiterung des Bindegewebes sich bei den mannigfaltigsten Krankheitsprocessen finden können, welche durch Infection, Intoxication, Marasmus, Kachexie, selbst Senium den Organismus schädigen. Es liegt kein Grund vor, zu bezweifeln, dass die Fasern des sympathischen Nervensystems sich nicht gerade so verhalten sollten, wie die peripherischen Nerven.

Nun lässt sich aber sehr schwer sagen, wie viel von dem pathologischen Befunde im II. Falle auf die genannten Processe der Intoxication und Kachexie zurückzuführen ist, und es bleibt somit nur die Analogie mit dem Falle I übrig, wonach ohne Zweifel angenommen werden muss, dass der grösste Theil des pathologischen Befundes am sympathischen und cerebrospinalen Nervensystem auf Rechnung der Addison'schen Krankheit zu schreiben ist.

Um schliesslich die Zahl der Zweifel vollständig zu machen, sei mir noch gestattet, im Allgemeinen auf die Bedeutung der Degenerationsprocesse im Sympathicus hinzuweisen.

Nach den heutigen Anschauungen der Nervenphysiologie ${ }^{2}$ ) stellt

1) Beiträge zur Pathologie der Tabes dorsalis. Arch. f. Psychiatrie. Bd. XVIII.

2) Vgl. Sigmund Mayer, Specielle Nerrenphysiologie. Hermann's Handbuch II. 1. 
der Sympathicus nichts Anderes dar, als eine vom cerebrospinalen Nervensystem abgezweigte Bahn.

Ueber die Bedeutung und die Functionen der sympathischen Ganglien, insbesondere derjenigen der grossen Plexus der Bauchhöble, sind von Pincusis), Budge ${ }^{2}$ ), Adrians), Schmidt4), Samuel ${ }^{5}$ ), Lamansky ${ }^{6}$ ), Munk und Klebs ${ }^{7}$ ), Peiper ${ }^{8}$ ) u. A. vielfach Untersuchungen angestellt worden, ohne dass übereinstimmende Resultate erzielt worden wären. Immerhin ist die Thatsache constatirt worden, dass die gangliösen Plexus der Bauchböhle zum Fortbestand des Lebens nicht unbedingt nothwendig seien. Wenn man auch diesen gewaltigen Ganglienmassen - im Gegensatz zu manchen nur mikroskopisch nachweisbaren, sogenannten automatischen Ganglienbäufchen im Herzmuskel, im Darm, in Drüsen u. s. w. - die Eigenschaft abspricht, Filialstellen von Gehirn und Rückenmark zu sein und centrale Functionen zu besitzen, und wenn man auch ihre Fähigkeit leugnet, automatisch oder reflectorisch bestimmte coordinirte Bewegungen oder Secretion auszulösen oder vom Gehirn oder Rtickenmark erhaltene Erregungen in bestimmter Weise umzuprägen, so ist der Schluss doch nicht gerechtfertigt, dass die sympathischen Ganglien ganz ohne bestimmte Function oder gar ohne Bedeutung iuberhaupt seien.

Im Gegensatz zu der grossen Bedeutung der sympathischen Fasersysteme, denen man eine hohe physiologische Dignität und namentlich die Fähigkeit zuschreibt, nervöse Impulse bestimmter Natur, wie trophische, vasomotorische, fortzuleiten u. dgl., vermuthet Si g mu nd Mayer (l. c.), dass die sympathischen Ganglien im Wesentlichen nur Ueberreste darstellen einer Bildungssubstanz für die Nervenfasern. „Ebenso erschien es mir, dass noch während des Lebens des erwachsenen Thieres im peripheren Nervensystem fortwährend Processe der Ruckbildung und Neubildung vor sich geben, und dass hierbei die periphere Nervenzelle eine bedeutende Rolle spielt. Letztere Ansicht glaube ich noch besonders dadurch stutzen zu können, dass die Nervenzellen Gebilde von ausserordentlich

1) Experimenta de vi nervi vagi et sympatb. etc. Breslau 1854.

2) Verhandlungen der Kais. Leop.-Carol. Akad. 1860. S. 255.

3) Eckhardt's Beiträge zur Anatomie und Physiologie. 1862. III. 1.

4) Ueber die Functionen des Plex. mes. post. Diss. Giessen 1862.

5) Wiener med. Wochenschrift 1856. Nr. 30.

6) Zeitschrift für rat. Medicin. XXVIII. 1866. S. 59.

7) Handb. d. path. Anat. I. 2. S.547.

8) Exper. Studien über die Ausrottung des Plexus coeliac. Deutsche Zeitschr. f. klin. Med. 1890. XVII. S. 498. 
wechselnder Grösse, verschiedenem Gehalte an Pigment und Fett und endlich von sehr wechselnder Zabl sind." (S. Mayer.) - Demnach hätten die Ganglienzellenanhäufungen nur in den vegetativen Process des Nervensystems einzugreifen.

Dem Gesagten zufolge müsste von der Summe der oben beschriebenen pathologischen Befunde ein weiterer Abzug gemacht werden. Nachdem ich auch dieses durch Vergleichen meiner Präparate mit den diesbezüglichen Abbildungen in dem bekannten Werke von A. Key und G. Retzius') und durch Vergleichen mit normalen Sympathicuscontrolpräparaten gethan habe, ist immer noch ein beachtenswerther Rest eines positiven Befundes übrig geblieben. Bei keinem der. Vergleichspräparate habe ich Pigmentatrophie und sonstige Degenerationsprocesse an den Ganglienzellen, circumscripte Entzündungsherde, Bindegewebshyperplasie in annähernd äbnlichem Grade gesehen, wie in meinen beiden Fällen; spindelförmige Auftreibungen, mehr oder weniger zablreiche Varicositäten an sympathischen Nervenfasern waren an Vergleichspräparaten aus sogenannten normalen Fällen wohl da und dort nachweisbar, nirgends aber eine Degeneration von sympathischen Nervenfasern in einer Ausdehnung und Intensität, wie ich sie für die Sympathicusgrenzstränge und Splanchnici bei den 2 Fällen von Addison'scher Krankheit beschrieben habe.

Den Befund an den Intervertebralganglien anlangend, so habe ich auch bier nicht unterlassen, Vergleiche anzustellen mit Schnitten von normalen und anderswie pathologischen Fällen (Syringomyelie). Nirgends habe ich Bilder gefunden, welche mit den an den Spinalganglien beschriebenen Veränderungen hätten in Parallele gestellt werden können.

Aus allen diesen Grtinden halte ich mich daher für berechtigt, einen Zustand chronischer Entzundung, welcher, von den degenerirten Nebennieren aufsteigend, seine höchsten Grade in den Semilunarganglien des Sympathicus und in den Intervertebralganglien darbietet und in geringeren Intensitätsgraden in den Ganglien des Brustsympathicus und in den Cervicalganglien nachweisbar ist, und welcher neben den Veränderungen am Bindegewebe besonders in einer intensiven Atrophie der Ganglienzellen und in einer ausgedehnten Degeneration holm 1876.

1) Studien in der Anatomie des Nervensystems und des Bindegewebes. Stock- 
markhaltiger Nervenfasern im Sympathicus und in den Splanchnicis ${ }^{1}$ ) zum Ausdrucke kommt, als charakteristisch für Addison'sche Krankheit anzusehen. Mit grosser Wahrscheinlichkeit sind Degenerationserscheinungen an den sensiblen Nerven und an den hinteren Wurzeln abbängig von den patbologischen Veränderungen an den Spinalganglien.

Ob die Befunde am Rückenmark, welche so wenig ausgesprochen sind, auf individuellen Eigenthtimlichkeiten oder zufälligen Härtungsanomalien beruhen, oder ob sie einer Fortleitung des Degenerationsprocesses von den binteren Wurzeln auf das Ruickenmark entsprechen, vermag ich noch nicht zu entscheiden. Ebensowenig vermag ich wegen der zu spärlichen Zabl in vorliegenden Beobachtungen die Frage bestimmt zu beantworten, ob das geschilderte Verbalten des Centralcanals, bezw. des Ependymfadens im Rückenmark ein zufälliges ist, oder ob es einem Verschlusse des Centralcanals entspricht, wie Burresi, Semmola und Tizzoni ihn beschrieben haben, und welchem namentlich der letztgenannte Autor so grosse Bedeutung beilegen zu müssen glaubt.

Mit dem allgemeinen Hinweise auf den Zusammenhang der klinischen Erscheinungen der Addison'schen Krankheit mit den beschriebenen pathologischen Befunden, wie ich ibn gelegentlich meines Vortrages in Wiesbaden gegeben habe, glaube ich mich vorerst begnügen zu müssen, bis weitere Untersuchungen meine Angaben bestätigt haben werden. Ueberdies existiren bereits genügende, wenn auch vorwiegend auf Hypothesen beruhende Versuche, die specielle Symptomatologie der Addison'schen Krankheit durch Veränderungen

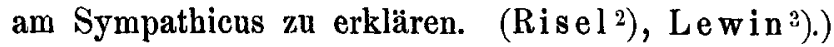

Nur einige Bemerkungen uber die Entstehung der Hautpigmentirung glaube ich hier noch zufligen zu müssen.

Auf Grund seiner eigenen Untersuchungen und unter Würdigung der Angaben anderer Autoren, vor Allen von Ehrmann, Riehl, v. Recklinghausen, ist Nothnage ${ }^{4}$ ) zu der Anschaung gelangt, dass das in den Retezellen abgelagerte Pigment aus dem Blute stamme. Es wird durch Wanderzellen dahin geftihrt, und der Weg lässt sich von den Blutgefässwandungen bis zum Rete Malpighi an der Hand anatomischer Präparate direct verfolgen.

1) 57. Versammlung deutscher Naturforscher und Aerzte zu Magdeburg. Sect. f. path. Anat. Ref. d. Berl. klin. Wochenschr. 1884. Nr. 51. S. 824.

2) Zur Pathologie des Morb. Addisonii. D. Arch. f. klin. Med. VII. S. 34 ff.

3) Charité-Annalen. 1884. IX. p. $619 \mathrm{ff}$.

4) Zur Pathol. d. Morb. Addisonii. Zeitschr. f. klin. Med. IX. 
Veränder. des sympath. u. cerebrospinal. Nervensyst. b. Addison'scher Krankh. 321

Dass es nicht freies Pigment ist, welches im Blute circulirt, wie man namentlich nach den Untersuchungen B rown-Séquard's ${ }^{1}$ ) vermuthet hat, ist schon lange feststehende Thatsache, da man niemals bei Addison'scher Krankheit melanämieähnliche Befunde constatirt bat. Auch bei meinen Befundsbeschreibungen babe ich darauf hingewiesen, dass sich in keinem Organe irgend ein Anhaltspunkt ergeben hat, welcher die Annahme rechtfertigen könnte, das Pigment wäre als solches schon im Blate vorhanden gewesen. Es milssen also rothe Blutkörperchen selbst sein, welche, aus den Gefässen tretend, ibr Pigment an Wanderzellen abgeben.

Was veranlasst aber einerseits die rothen Blutkörperchen, die Gefässbahn zu verlassen, andererseits die Wanderzellen, das Pigment aufzunehmen und nach der Epidermis bin zu transportiren, wie es bei der Addison'schen Krankheit der Fall ist?

Nothnagel spricht sich ganz allgemein dahin aus, dass bei der Addison'schen Krankheit gewisse nervöse Einflüsse die Coriumzellen veranlassen, so viel Pigment aufzunehmen, weniger etwa durch directe Beeinflussung der Coriumzellen selbst, als durch bestimmte Einwirkung auf die Blutgefässe der Haut.

Ieh werfe nun hier die Frage auf, ob die von Nothnagel supponirten Nerveneinflïsse nicht im pathologischen Verbalten des sympathischen Nervensystems, der Spinalganglien und der peripheren Nerven gegeben sind. Im Sympathicus verlaufen bekanntlich vorwiegend trophische und vasomotorische Fasern, auch in den Spinalganglien werden trophische Centren vermuthet. Ich erinnere in letzterer Hinsicht nur an die angioneurotischen Veränderungen der Haut bei Herpes zoster, welcher Erkrankung entzundliche Processe in den Spinalganglien oder neurotisehe Processe zu Grunde liegen sollen. (v. Baerensprung, Auspitz2). Unter dem Hinweis auf die beschriebenen Befunde läge daher eine gewisse Berechtigung vor, die Pigmentirung bei der Addison'schen Krankheit als einen angioneurotischen, bezw. trophoneurotischen Process zu bezeichnen. ${ }^{3}$ )

1) a) Recherches expérimentales sur la physiologie et la path. des caps. surrénales. Archiv. gén. de méd. 1856. - b) Note sur les caps. surrénales. Archiv. gén. de méd. 1857. I.

2) Allg. Path. d. Haut. Ziemssen's Handbuch. XIV. 1.

3) Bei der Correctur hat Herr Prof. Strümpell die grosse Güte gehabt, mich auf die Arbeit von Gaule: "Spinalganglien und Haut" im Centralblatt für Physiologie vom 30. Januar d. J. aufmerksam zu machen. Aus dieser Arbeit Gaule's geht mit aller Sicherheit hervor, dass nach der Verletzung der Spinalganglien beim Frosche trophische Störungen in der Haut auftreten, welche constant mit Veränderungen in der Pigmentirung einhergehen. 
Eine letzte Frage, welche ich hier nicht unerörtert lassen kann, ist die nach der eigentlichen Aetiologie der Addison'schen Krankheit.

Es sind ganz verschiedenartige Krankheitsformen, welche sich in den Nebennieren etabliren können: die einen, z. B. die tuberculösen, bringen mit einer gewissen Regelmässigkeit die Ausbildung des merkwürdigen Symptomencomplexes zu Stande, während andere dies nicht zu thun vermögen.

Ich habe (l. c.) eine von den Nebennieren zum sympathischen und durch dieses zum spinalen Nervensystem aufsteigende Entzündung, welche auf ihrem ganzen Wege von intensiver Degeneration markhaltiger Fasern begleitet ist, für sehr wesentlich gehalten und aus diesem Grunde Affectionen der Nebennieren, welche von Entzündungserscheinungen nicht begleitet sind, als ungeeignet bezeichnet, den Addison'schen Symptomencomplex auszulösen. Als Beweise für die letzterc Annahme sollten die Fälle von Blutungen, Amyloiddegeneration, manche Fälle von Carcinom der Nebennieren dienen, welche unverbältnissmässig viel seltener als z. B. die Tuberculose zu Addison'scher Krankheit fuhren.

Ein Entzündungsprocess ähnlicher Art könne (1. c.) auch im sympathischen Nervensystem selbst seinen Ausgangspunkt nehmen oder von einem anderen Orte auf den Sympathicus übergreifen, während histologiseh die Nebennieren dabei intact blieben. In meinem II. Falle griff z. B. der von Entztindungserscheinungen begleitete Krankheitsprocess vom Plexus solaris auf die rechte Seite tuber, und es zeigte sich daher der rechte Sympathicus gerade so verändert, wie der linke, obwohl die rechte Nebenniere intact war. (Vgl. Aran $\left.{ }^{1}\right)$, Bell. Fletcher $\left.{ }^{2}\right)$.)

Wenn man nun die Annahme nicht gelten lassen will, dass sich die Nebennieren beim Entstehen der Addison'schen Krankheit ganz passiv verhalten, trotz der in ihrem Marke sich abspielenden Entzündungsprocesse, drängt sich unwillkturlich die Frage auf, ob ibnen nicht doch eine gewisse Rolle bei der Ausbildung dieses Symptomencomplexes zuzuschreiben sei. Ich erinnere hierbei nur an den Nachweis chemisch nicht indifferenter Körper und Farbstoffe in den Nebennieren (Vulpian, Cloezu. Vulpian, Virchow, Arnold) und an die innigen Beziehungen der Nebennieren zum Nerven- und Blutgefässsystem. Dabei erscheint dann die Annahme der Circulation eines chemisch nicht indifferenten Körpers im Blute und eine bestimmte degenerirende Einwirkung desselben auf das Nervensystem,
1) Gazette des hôpit. 1868 .
2) Brit. med. Journ. 1857. 
auf das Herz und die Gefässe nicht mehr so sehr abenteuerlich. Man wird sogar am so mehr an eine ganz specifische Einwirkung eines bestimmten Stoffes auf das Nervensystem, besonders auf den Sympathicus glauben miissen, als eine grosse Zahl von pathologischen Befunden am Sympathicus beschrieben sind (Lubim off berichtet von 250, Poa Foa von 140 solchen Fällen) bei Fällen, wo Anzeichen von Addison'scher Krankheit gefehlt haben.

Auch ein Vergleich des Addison'schen Symptomencomplexes mit dem ebenfalls noch verschleierten Bilde der Cachexia strumipriva, des Myxödems und der Tetanie hat unter den angedeuteten Prämissen eine gewisse Zulässigkeit.

Die Functionen der Schilddrüse sind uns noch gerade so unbekannt, wie diejenigen der Nebennieren. Die krankhaften Veränderungen, sogar die Exstirpation dieser Organe (- wenigstens der Schilddritise -) haben aber gleichwohl einen mächtigen Einfluss auf die Oekonomie des Organismus, einen Einfluss, welcher in den genannten Krankheitsbildern zur Aeusserung gelangt, und dessen Entstehung in letzter Linie auf ein chemisch wirksames Agems unbekannter Natur zurilckgefuhrt werden muss.

Nach der Definition Rossbach's ') ist die Addison'sche Krankheit „eine Neurose, d. h. eine anatomisch bis jetzt nicht nachweisbare functionelle Störung des gesammten Nervensystems, welche in näherer, aber nicht nothwendiger Beziehung zu den Nebennieren steht und sich durch Störungen der Psyche, hochgradige Anämie, ausserordentliches Schwächegefühl und sehr bäufig durch eine dunkle Pigmentirung der Haut charakterisirt". Symptome und Befunde der Addison'schen Krankheit bringt Rossbach ausserdem noch in innigste Beziehung mit der Selerodermie. Nach den Untersuchungen Dink ler's ist aber die Sclerodermie wahrscheinlich auf eine Gefässerkrankung zurückzufuhren, während meinen Auseinandersetzungen zufolge die Addison'sche Krankheit auf einer pathologisch nachweisbaren Affection des Nervensystems beruht, deren Ausgangspunkt nach den Nebennieren zu verlegen ist.

Am Schlusse meiner Arbeit ist es mir eine angenehme Pflicht, Herm Prof. Erb und Herrn Prof. Arnold für die freundliche Ueberlassung des klinischen und pathologischen Materiales herzlichsten Dank auszusprechen.

Heidelberg, October 1891.

1) Addison'sche Krankheit und Sclerodermie. Virchow's Archiv. Bd. L. S. 51. 
324 XVI. FLFINER, Veränder. des sympath. u. cerebrospinal. Nervensyst.

\section{Erklärung der Abbildnngen.}

Fig. 1. Schnitt aus dem Gangl. semilunare des Falles I. Zeiss A, Oc. 3.

a) Kleinzellige Infiltrationsherde in der Umgebung eines Gefässes.

b) Rundzellenanhäufung zwischen den Ganglienzellen.

c) Zerfall des Markmantels von Nervenfasern.

Fig. 2. Längsschnitt vom Nervus splanchnic. major sinist. mit Waller'scher Degeneration von Nervenfasern. Zeiss A. Oc. 3.

Fig. 3. Segment eines Längsschnittes durch ein Spina lganglion. Beträchtliche Verdickung der fibrösen Hülle und des interstitiellen Bindegewebes mit Pigmentirung. Hochgradige Pigmentatrophie der Ganglienzellen. Zeiss A. Oc. 3 .

Fig. 4. Längsschnitt durch ein Spinalganglion mit den zugehörigen Nerven (etwas schematisirt).

$h w=$ hintere Wurzel mit mässiger Degeneration markhaitiger Fasern.

r.c. Verbindungsast des Ganglion mit dem Sympathicus am stärksten degenerirt.

n.i. Zum Intercostalnerv gehender Nervenstamm.

Fig. 5. Rückenmarksquerschnitte des Falles I in natürlicher Grösse mit den nach der Härtung in Müller'scher Flüssigkeit sichtbaren hellen Feldern in den Hintersträngen.

Fig. 6. Rückenmarksquerschnitte des Fallss II in natürlicher Grösse mit den nach der Härtung in Müller'scher Flüssigkeit hellen Feldern in den Hintersträngen. 


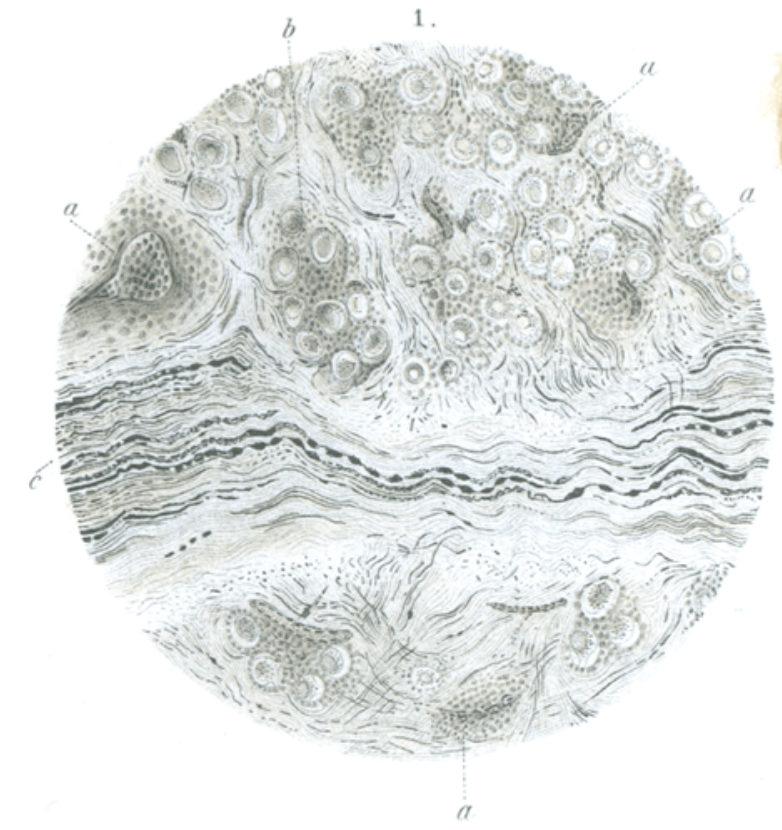

2.
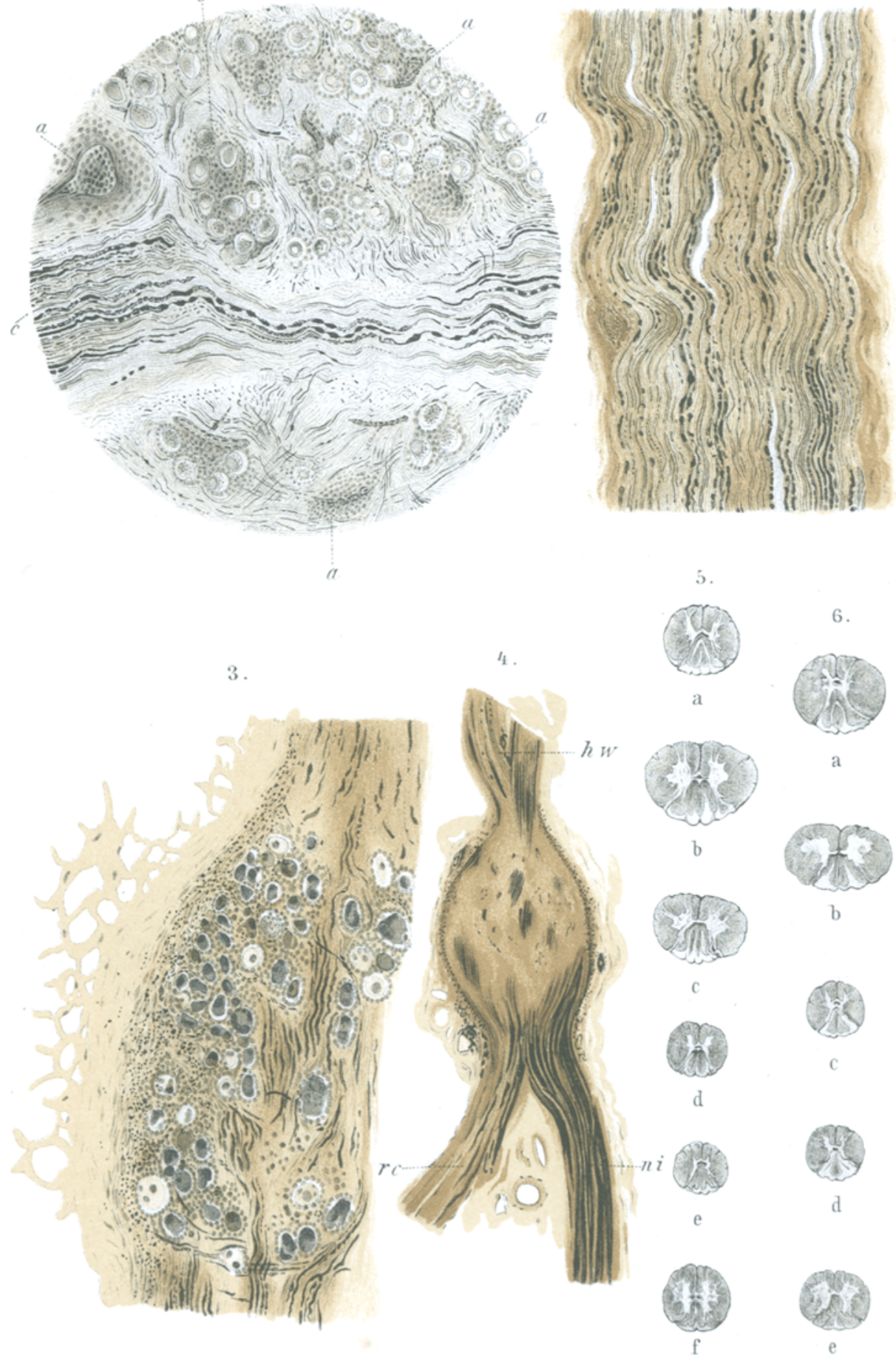

Fleiner, Addisonsche Kran 3 heit. 